\title{
Recovery and validation of Odin/SMR long-term measurements of mesospheric carbon monoxide
}

\author{
Francesco Grieco ${ }^{1}$, Kristell Pérot ${ }^{1}$, Donal Murtagh ${ }^{1}$, Patrick Eriksson $^{1}$, Peter Forkman ${ }^{1}$, Bengt Rydberg $^{2}$, \\ Bernd Funke $^{3}$, Kaley A. Walker ${ }^{4}$, and Hugh C. Pumphrey ${ }^{5}$ \\ ${ }^{1}$ Department of Space, Earth and Environment, Chalmers University of Technology, Gothenburg, 412 96, Sweden \\ ${ }^{2}$ Molflow, Gråbo, 443 40, Sweden \\ ${ }^{3}$ Instituto de Astrofísica de Andalucía, CSIC, Granada, Spain \\ ${ }^{4}$ Department of Physics, University of Toronto, Toronto, M5S 1A7, ON, Canada \\ ${ }^{5}$ School of Geosciences, University of Edinburgh, Edinburgh, EH9 3FF, UK
}

Correspondence: Francesco Grieco (francesco.grieco@chalmers.se)

Received: 19 February 2020 - Discussion started: 4 March 2020

Revised: 7 July 2020 - Accepted: 31 July 2020 - Published: 25 September 2020

\begin{abstract}
The Sub-Millimetre Radiometer (SMR) on board the Odin satellite performs limb sounding measurements of the middle atmosphere to detect molecular emission from different species. Carbon monoxide (CO) is an important tracer of atmospheric dynamics at these altitudes, due to its long photochemical lifetime and high vertical concentration gradient. In this study, we have successfully recovered over 18 years of SMR observations, providing the only dataset to date being so extended in time and stretching out to the polar regions, with regards to satellite-measured mesospheric $\mathrm{CO}$. This new dataset is part of the Odin/SMR version 3.0 level 2 data. Much of the level 1 dataset - except the October 2003 to October 2004 period - was affected by a malfunctioning of the phase-lock loop (PLL) in the front end used for $\mathrm{CO}$ observations. Because of this technical issue, the $\mathrm{CO}$ line could be shifted away from its normal frequency location, causing the retrieval to fail or leading to an incorrect estimation of the $\mathrm{CO}$ concentration. An algorithm was developed to locate the $\mathrm{CO}$ line and shift it to its correct location. Nevertheless, another artefact causing an underestimation of the concentration, i.e. a line broadening, stemmed from the PLL malfunctioning. This was accounted for by using a broader response function. The application of these corrections resulted in the recovery of a large amount of data that was previously being flagged as problematic and therefore not processed. A validation study has been carried out, showing how SMR CO volume mixing ratios are in general in good accordance with the other instruments considered in the study. Overall, the agree-
\end{abstract}

ment is very good between 60 and $80 \mathrm{~km}$ altitude, with relative differences close to zero. A positive bias at low altitudes $(50-60 \mathrm{~km})$ up to $+20 \%$ and a negative bias up to $-20 \%$ at high altitudes $(80-100 \mathrm{~km})$ were found with respect to the comparison instruments.

\section{Introduction}

Of the carbon monoxide (CO) produced at surface level by anthropogenic sources (e.g. industrial activities, biomass burning, transport and heating) as well as by oceans and biogenic sources, very little is transported upwards to the stratosphere, as it is chemically destroyed by reacting with the hydroxyl radical $(\mathrm{OH})$. This causes a sharp gradient in $\mathrm{CO}$ concentration from the troposphere to the lower stratosphere (Zander et al., 1981). The CO which can be observed in the middle atmosphere is mainly produced via two processes: methane $\left(\mathrm{CH}_{4}\right)$ oxidation and $\mathrm{CO}_{2}$ photolysis, with the latter being the dominant one (Minschwaner et al., 2010). In particular, high altitudes are characterised by strong fluxes of radiation in the Schumann-Runge bands and continuum and Lyman- $\alpha$ wavelengths which are strongly absorbed by $\mathrm{CO}_{2}$; therefore, $\mathrm{CO}_{2}$ photolysis becomes more significant with height in the upper mesosphere and lower thermosphere, providing a major source of $\mathrm{CO}$ and resulting in a large vertical gradient in its concentration. $\mathrm{CO}$ from high altitudes is transported downwards in the winter hemisphere polar night 
region due to advection and vertical eddy mixing (Solomon et al., 1985). In the mesosphere and lower thermosphere, the photochemical lifetime of $\mathrm{CO}$ increases with altitude from a minimum of approximately 1 week up to several hundreds of years. This lifetime is greater than the zonal transport timescale and of the same order of magnitude as the meridional and vertical transport timescales in the stratosphere up to the middle mesosphere, while it is significantly greater than all transport timescales in the upper mesosphere (Brasseur and Solomon, 2005). Because of its strong horizontal and vertical concentration gradients and due to its long lifetime, $\mathrm{CO}$ is commonly used as a tracer of middle atmospheric dynamics (e.g. Lee et al., 2011; de Zafra and Muscari, 2004).

Measurements of $\mathrm{CO}$ in the mesosphere have been carried out since the end of the 1970s using ground-based instruments (Clancy et al., 1982) and later on with satellites such as UARS/ISAMS (Allen et al., 1999). More recent satellite measurements are the ones performed in the microwave band with Aura/MLS (e.g. Froidevaux et al., 2006), as well as in the infrared with Envisat/MIPAS (e.g. Funke et al., 2009) and SCISAT-1/ACE-FTS (e.g. Clerbaux et al., 2008). The first retrieval results from $\mathrm{CO}$ measurements obtained with the Sub-Millimetre Radiometer (SMR) on board Odin were presented by Dupuy et al. (2004). They observed seasonal variations of $\mathrm{CO}$ concentration related to global circulation and chemical processes as predicted from the Whole Atmosphere Community Climate Model (WACCM), to which they compared their results obtaining an overall agreement within 2 orders of magnitude. Also, good agreement has been obtained comparing with observations from UARS/ISAMS.

There are not many studies about Odin/SMR measurements of $\mathrm{CO}$, although such measurements have been performed from August 2001 until today. This is due to a malfunctioning of the phase-lock loop (PLL) in the front end used for $\mathrm{CO}$ observations, which caused the majority of $\mathrm{CO}$ data to present artefacts which made them unusable for retrievals. The issue is illustrated in Sect. 2 together with a description of Odin/SMR. In Sect. 3 we explain how we implemented a correction for the artefacts caused by the PLL malfunctioning and other issues which arose during the retrieval process. As a result, retrieval products from over 18 years of Odin/SMR CO observations, between 50 and $100 \mathrm{~km}$ altitudes, are now available and presented in Sect. 4. They are part of the Odin/SMR v3.0 L2 dataset. Finally, for validation purposes, in Sect. 5 we compare Odin/SMR profiles with those from Envisat/MIPAS, SCISAT-1/ACE-FTS and Aura/MLS, being the satellite instruments operating at the same time as SMR and observing similar altitudes. We also present comparisons with ground-based measurements from the Onsala Space Observatory.

\section{Odin/SMR CO measurements}

\subsection{The Sub-Millimetre Radiometer}

The Odin satellite, a Swedish-led project in collaboration with Canada, France and Finland, was launched on 20 February 2001 into a $600 \mathrm{~km}$ sun-synchronous orbit with inclination $97.77^{\circ}$ and 18:00 LT ascending node. Its observation time was shared between astronomical and atmospheric observations until 2007, when the astronomical part of Odin's mission was concluded. After that, the instruments on board Odin have been used exclusively for limb sounding of the atmosphere. These instruments are OSIRIS (Optical Spectrograph and InfraRed Imaging System) and SMR. In this article, we are using the latter. The four sub-millimetre receivers in SMR can be tuned to cover frequencies between 486-504 and $541-581 \mathrm{GHz}$, thus to observe emission due to rotational transitions for species such as $\mathrm{O}_{3}, \mathrm{H}_{2} \mathrm{O}, \mathrm{CO}, \mathrm{NO}, \mathrm{ClO}, \mathrm{N}_{2} \mathrm{O}$ and $\mathrm{HNO}_{3}$ in the stratosphere and mesosphere (e.g. Frisk et al., 2003). There is also a millimetre receiver to observe the $118 \mathrm{GHz} \mathrm{O}_{2}$ transition. The cold sky and a hot load are repeatedly observed for calibration purposes (see Fig. 1). A Dicke switch allows us to quickly change the source of the signal between the main beam and the calibrators. The signal is thereafter split according to polarisation and injected into the mixer through a Martin-Puplett interferometer. Here the source signal is converted to longer wavelengths by combining it with a local oscillator (LO) signal, also injected through the Martin-Puplett interferometer. The frequency of the LO is fine tuned with the use of a PLL. The output signal of the mixer is a function of the sum and difference of the frequencies of the input signals, therefore consisting of two sidebands. SMR is however run in single sideband mode so, of the two sidebands, only the one containing the signal of interest will be detected and the other one suppressed. This is achieved, before mixing, by accordingly setting the length of the arms of the Martin-Puplett interferometer. The resulting signal can then be amplified and routed to the autocorrelator spectrometers ( $\mathrm{AC} 1$ and $\mathrm{AC} 2$, as indicated in Fig. 1).

Measurements are performed during both upward and downward vertical scanning with a vertical sampling of $\sim$ $6 \mathrm{~km}$ in the mesosphere. The scanning is continuous, with a constant speed of $0.75 \mathrm{~km} \mathrm{~s}^{-1}$. Odin/SMR L1 data are organised in scans, each of them consisting of a group of spectra collected during a single upward (or downward) scanning. Each spectrum corresponds to a single mean tangent altitude in the range $7-72 \mathrm{~km}$ (stratospheric scans), $7-110 \mathrm{~km}$ (strato-mesospheric scans) or $60-110 \mathrm{~km}$ (mesospheric scans) (Dupuy et al., 2004).

\subsection{SMR CO operational modes}

Odin/SMR measures $\mathrm{CO}$, with a $3-7 \mathrm{~km}$ vertical resolution, from the thermal emission line corresponding to the $J=5 \rightarrow 4$ rotational transition at $576.268 \mathrm{GHz}$. In Fig. 2a 


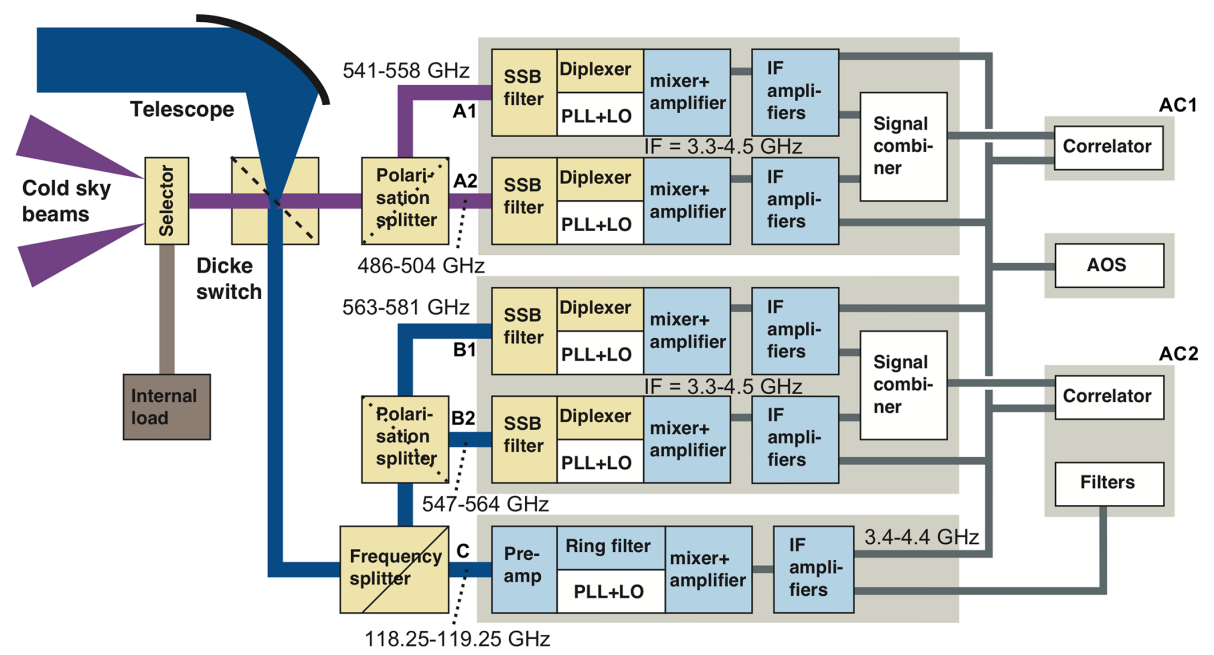

Figure 1. Block diagram of the Odin radiometer. From Frisk et al. (2003).

we show an illustrative scan of spectra obtained in normal conditions where both a $\mathrm{CO}$ line and an $\mathrm{O}_{3}$ line are measured. The SMR receivers can be adjusted to different configurations called frequency modes (FMs), each of which corresponds a certain observed frequency band and a scheduled observation time. There are three FMs that cover bands in which the above-mentioned CO transition is observed. Their characteristics are summarised in Table 1. All these measurements are carried out by using the B1 front end (the set of components thus denoted in Fig. 1), whose PLL element was working correctly for a year only, between 8 October 2003 and 8 October 2004. The measurements made during the rest of the Odin operational time, from 2001 until today, have all been affected by a malfunctioning of this PLL, leading to a shift of the LO frequency from its nominal value (Rydberg et al., 2017). Consequently each scan presents a different frequency shift. In extreme cases like the one shown in Fig. 2b, the frequency shift causes the $\mathrm{CO}$ line to fall outside the observed bandwidth, and thus the data are unrecoverable.

\section{Recovery and retrieval}

We explain here how we developed a frequency correction which was applied to the spectra before the retrieval process, leading to the recovery of a great part of the dataset. This is followed by descriptions of the set-up for the v3.0 CO retrievals and of the method used to estimate line broadening generated by the PLL failure.

\subsection{Basic frequency correction}

In order to correct the frequency shift, as a first step, the centre frequency of the $\mathrm{CO}$ line in the scan's average spectrum has been compared with the theoretical centre frequency. The resulting difference is then applied to the LO frequency. To do that, the correction algorithm first needs to distinguish the $\mathrm{CO}$ line from the $\mathrm{O}_{3}$ line. In Fig. 3a it is shown how peak brightness temperatures of $\mathrm{CO}$ and $\mathrm{O}_{3}$ lines vary with altitude. Here it can be noticed that the $\mathrm{CO}$ and $\mathrm{O}_{3}$ slopes are most different between 40 and $60 \mathrm{~km}$, allowing us to discern between the two species. In Fig. 3b, averaging of observations during the PLL working period show that, in this altitude range, $\mathrm{a}-0.0004 \pm 0.001 \mathrm{~K} \mathrm{~m}^{-1}$ slope corresponds to the $\mathrm{CO}$ line, while the value $-0.009 \pm 0.003 \mathrm{~K} \mathrm{~m}^{-1}$ identifies the $\mathrm{O}_{3}$ line, where the uncertainties on slopes correspond to $3 \sigma$. Thus, the correction algorithm associates peak $T_{\mathrm{b}}$ gradients with a value higher than $-0.0045 \mathrm{~K} \mathrm{~m}^{-1}$ to the $\mathrm{CO}$ line. The LO frequency can then be corrected for the whole altitude range under consideration in this study, as explained above. If no line or only the $\mathrm{O}_{3}$ line is found, the scan is not considered for further processing.

Despite the application of this first correction to the data, they still present artefacts that need to be corrected. In fact, as can be seen in Fig. 4a, all spectra in a single scan, each corresponding to a different altitude, present a different frequency shift. This suggests that the PLL malfunctioning affects the observation at a timescale smaller than the scanning timescale $(\sim 2 \mathrm{~min})$. Thus applying the same correction to each spectrum in a scan is not sufficient. To solve this problem, we modified the pre-correction algorithm by considering each single-altitude spectrum and estimating the observed centre frequency of each $\mathrm{CO}$ line by fitting them with a Gaussian function. We then compared these values to the theoretical centre frequency and therefore applied a different shift to each spectrum. An example of result obtained from this correction is shown in Fig. 4b. Including this altitude-dependent correction resulted in a significantly increased amount of data that could be recovered, i.e. from which $\mathrm{CO}$ concentration profiles could be derived (as shown in Fig. 7 in Sect. 4). The frequency shifts, of which we pre- 
Table 1. FMs for observing CO. From Rydberg et al. (2017).

\begin{tabular}{lrrrlr}
\hline Frontend & Spectrometer & LO freq. (GHz) & Freq. range $(\mathrm{GHz})$ & Species & FM \\
\hline \multirow{2}{*}{$572 \mathrm{~B} 1$} & \multirow{2}{*}{$\mathrm{AC} 2$} & 572.762 & $576.062-576.862$ & $\mathrm{CO}, \mathrm{O}_{3}$ & 14 \\
\cline { 3 - 6 } & & 572.964 & $576.254-576.654$ & $\mathrm{CO}, \mathrm{O}_{3}$ & 22 \\
& & & $577.069-577.469$ & $\mathrm{HO}_{2},{ }^{18} \mathrm{O}_{3}$ & \\
\cline { 2 - 6 } & $\mathrm{AC} 1$ & 572.762 & $576.062-576.862$ & $\mathrm{CO}, \mathrm{O} 3$ & 24 \\
\hline
\end{tabular}

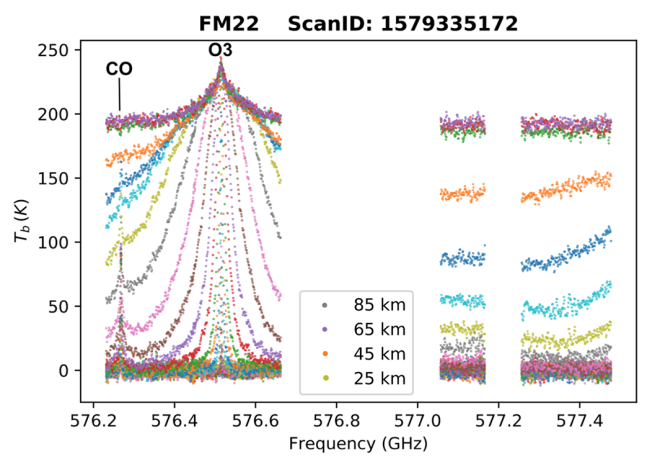

(a)

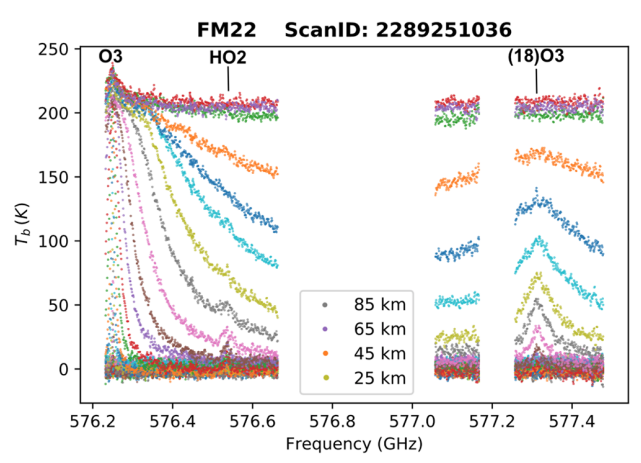

(b)

Figure 2. Spectra for altitudes ranging from 7 to $110 \mathrm{~km}$ for two scans taken as examples. The bigger gap in the spectra around $576.8 \mathrm{GHz}$ is due to the particular way the bands are arranged to cover the desired frequencies for FM22, while the smaller gap at $577.2 \mathrm{GHz}$ is due to instrumental failure relative to one sub-band. In (a) both $\mathrm{CO}$ and $\mathrm{O}_{3}$ lines are present and at the expected frequency. In (b) the frequency shift is so big that only the $\mathrm{O}_{3}$ can be observed (shifted), while the $\mathrm{CO}$ line is shifted outside of the band and therefore not observed. Colours corresponds to different tangent altitudes within the reported scan. Not all altitudes are indicated in the legend for the sake of readability.

sented the corrections in this section, appear to be random and not follow any trend with time. No dependency on satellite temperature was observed either.

\subsection{Retrieval set-up}

The Atmospheric Radiative Transfer Simulator (ARTS) retrieval algorithms are based on the optimal estimation method (Rodgers, 2000) from which statistical errors on the retrieved quantities originate. A new version of the ARTS operational processing system has been developed for SMR retrievals. The data produced by this system will be denoted as version 3.x. The new retrieval system will be described in detail in a forthcoming publication, but a summary is provided below. The $\mathrm{CO}$ data discussed in this work have been assigned version number 3.0.

The new processing system is based on a MySQL database and is capable of distributing the calculations over multiple clusters. The actual retrievals are based on ARTS (Buehler et al., 2018). For the moment ARTS version 2.3.564 is applied. Besides atmospheric radiative transfer, the forward simulations consider the sensor's antenna response, double-sideband characteristics and spectrometer frequency response, using the approach of Eriksson et al. (2006). ARTS provides the needed weighting functions (mainly using analytical expressions), while the inversion of optimal estima- tion type is made in MATLAB by code taken from Eriksson et al. (2005).

The L2 data provided contain a characterisation of the retrieval, following Rodgers (2000). As described in Baron et al. (2002), when retrieving multiple quantities in parallel, the "smoothing error" includes terms that describe the interference between the quantities. The retrieval error reported in SMR v3.0 data incorporates this cross-quantity interference but excludes the classical smoothing error internal to the quantity. For example, the error reported for $\mathrm{CO}$ considers that the retrieval of instrumental parameters is nonideal but excludes the direct smoothing of the $\mathrm{CO}$ profile due to limitations in vertical resolution. In this way, the reported error matches the standard one that would be obtained if the instrumental parameters would instead be treated as forward model uncertainties (though strictly true only for a totally linear inversion problem).

Specifics for the retrievals presented in this paper include that only spectra recorded at tangent altitudes between 40 and $100 \mathrm{~km}$ are considered to form a mesospheric retrieval mode. The spectroscopic data for the frequency range of concern is solely taken from HITRAN 2012 (Rothman et al., 2013) (but the system allows us to incorporate data from other sources). The set of variables retrieved is specified for each mode separately. In this case, the $\mathrm{CO}$ profile and off-sets for pointing, 


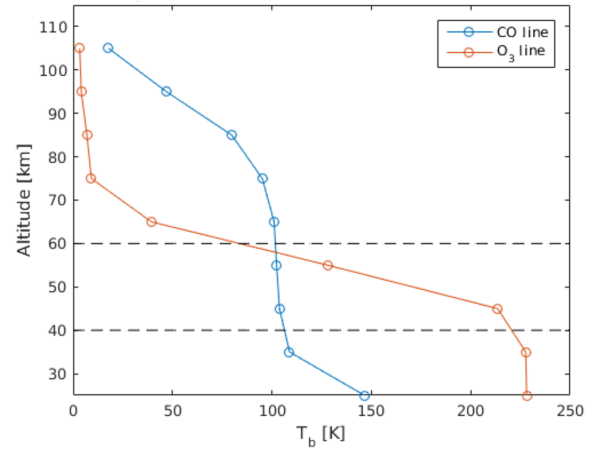

(a)

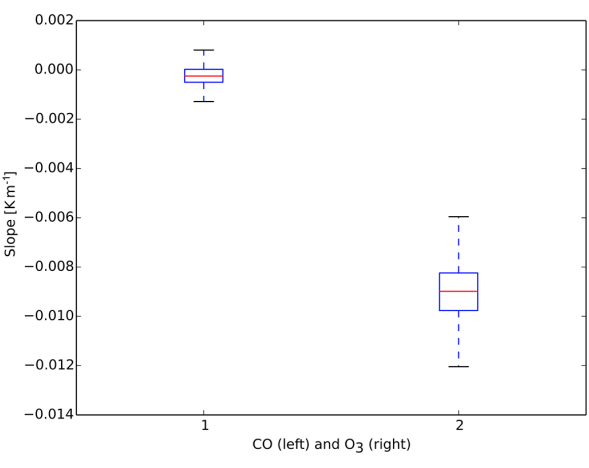

Figure 3. (a) Peak brightness temperatures of $\mathrm{CO}$ and $\mathrm{O}_{3}$ at different altitudes. Average considering all observations performed during the PLL working period, i.e. 14224 scans. At altitudes between 40 and $60 \mathrm{~km}$, the CO line curve presents a steeper slope. (b) Linear fit of slopes of peak brightness temperatures between 40 and $60 \mathrm{~km}$ altitude for $\mathrm{CO}$ and $\mathrm{O}_{3}$. The shown uncertainties on slopes correspond to $3 \sigma$.

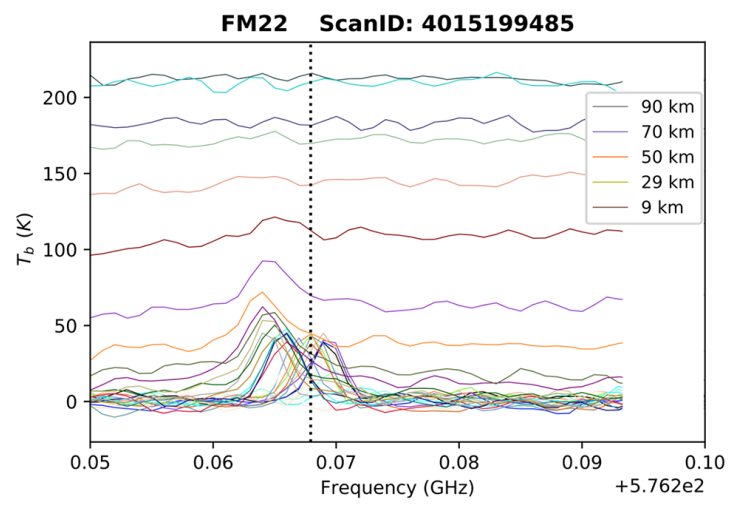

(a)

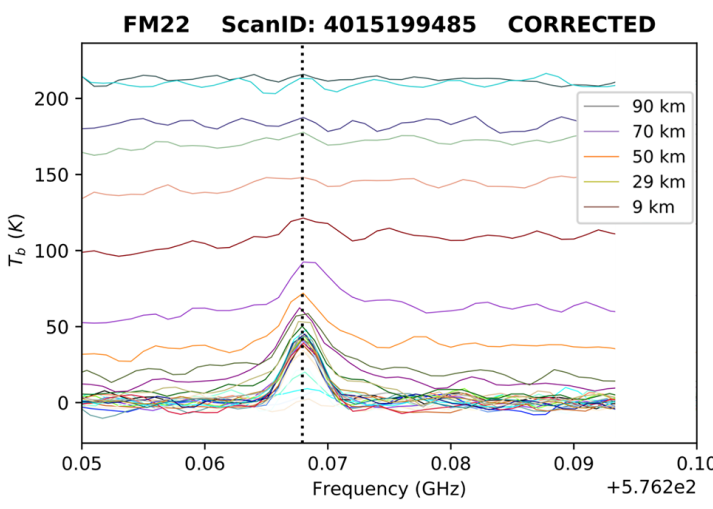

(b)

Figure 4. Spectra measured on 2 February 2009 presenting altitude-dependent frequency shifts before (a) and after (b) altitude-dependent correction. Colours corresponds to different tangent altitudes within the reported scan. Not all altitudes are indicated in the legend for the sake of readability.

frequency and brightness temperature zero level (baseline) are retrieved.

The a priori dataset previously used for Odin/SMR CO retrievals was found outdated and inaccurate. As a consequence, for the new inversions, a new CO climatology was formed, based on MIPAS zonal means averaged over the years separately for each month. For this purpose, we are using the product V5R_CO_521, which at the moment is the most recent data version from MIPAS middle atmosphere observation mode (Garcia et al., 2014) (see Sect. 5.1). The monthly a priori is divided into $10^{\circ}$ latitude bins. As a temperature model for the retrieval, ERA-Interim reanalysis data (Dee et al., 2011) are used up to $60 \mathrm{~km}$ and the Mass Spectrometer Incoherent Scatter model (version NRLMSISE-00; Picone et al., 2002) is used from $70 \mathrm{~km}$ upwards. Between 60 and $70 \mathrm{~km}$, a spline interpolation of the two is applied.

In Fig. 5 the retrieval for a typical scan is shown. Despite the fact that spectra above $40 \mathrm{~km}$ tangent altitude are considered in the inversion, only measurements above $50 \mathrm{~km}$ are re- liable since at lower altitudes it is not possible to discern the $\mathrm{CO}$ line from the noise. Moreover, data with a measurement response lower than 0.75 are discarded, where the measurement response is a measure of the degree to which the result may be contaminated by the a priori. It is defined as the sum over the row of the averaging kernel matrix (Rodgers, 2000). Values lower than 0.75 occur for the retrieved profile above $100 \mathrm{~km}$ which is dominated by the a priori and is here shown out of completeness, together with the averaging kernel extending to higher altitudes, to display how retrieved concentrations between 90 and $100 \mathrm{~km}$ are also influenced by higher altitudes.

\subsection{Broadening correction}

The fits of the $\mathrm{CO}$ line performed during the inversion process - which have the shape of a Gaussian function due to Doppler broadening - have significantly different amplitude and width compared to the observed line, causing an 


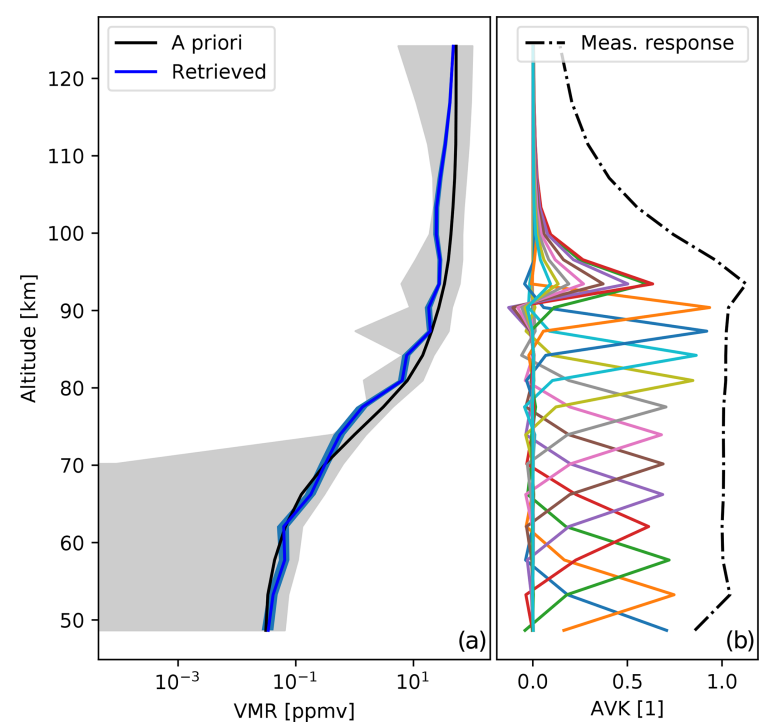

Figure 5. Example retrieval referring to ScanID 1579335172 from FM22. (a) Retrieved concentration profile and error (in blue) and a priori including uncertainties (in grey). (b) Averaging kernels plotted in a different colour for each altitude (not indicated) and measurement response.

underestimation of the concentration. This suggests that the PLL malfunctioning even has an effect within the integration time, causing the observed line to be broadened with respect to what it would be in normal instrumental conditions. To take into account this broadening issue during the inversion, the original response function, a Gaussian function with $\sigma=0.8 \mathrm{MHz}$, has been replaced with a Gaussian function with a higher $\sigma$ value. The response function $w_{\mathrm{ch}}^{i}(\nu)$ of a spectrometer's channel $i$ represents how the power of a signal $I(v)$ is weighted:

$y_{i}=\int_{0}^{\infty} I(v) w_{\mathrm{ch}}^{i}(v) \mathrm{d} v \quad$ with $\int_{0}^{\infty} w_{\mathrm{ch}}^{i}(v) \mathrm{d} v=1$

where $y_{i}$ is the final, calibrated antenna temperature of the channel $i$ (Eriksson et al., 2006).

Figure 6a shows the relative difference between the Gaussian area beneath the observed CO line and the Gaussian area beneath the fit, for a scan in the period when the PLL was working. Here there is no need for correction, and the lower values of the relative area difference are obtained with the original response function. As an example, in Fig. $6 \mathrm{~b}$ the relative area difference for one scan in the PLL malfunctioning period after 8 October 2004 is plotted. During this period, the most suitable response function is a Gaussian function with $\sigma=1.1 \mathrm{MHz}$. This is indeed the one resulting in the lowest overall relative area differences; therefore, this same response function has been used in the whole period aforementioned.
Note that the original response function is still the one giving the best results during the period before 8 October 2003 . Consequently, the new response function has been applied only to inversions after 8 October 2004. This suggests that the PLL malfunctioning before 8 October 2003 is of a different nature than the one after 8 October 2004, with the former causing only frequency shifts and the latter causing both line broadenings and frequency shifts, i.e. having effects both within the integration time and at longer timescales.

\section{The new dataset}

The recovered dataset is part of the Odin/SMR v3.0 L2 data. As mentioned in Sect. 3, the new frequency correction algorithm also helped to recover many data that were previously being erroneously flagged, so that there is a very significant increase in the amount of $\mathrm{CO}$ level 2 data that are now available. This can be seen in Fig. 7, showing the temporal distribution of the L1 and L2 datasets before and after the application of the correction algorithm, for the three $\mathrm{CO}$ observation modes together. The results are very satisfying, with $63 \%$ of the data being successfully processed (compared to $8 \%$ before the correction) until September 2017. The remaining data are discarded due to other quality flags. After this date, the frequency shift is causing the $\mathrm{CO}$ line of almost all the spectra to be outside of the observed band, resulting in the loss of most of the $\mathrm{CO}$ data during this time period, hence the almost total absence of L2 data from then on. The very high number of measurements performed with $\mathrm{CO}$ FMs during July 2002, July 2003 and August 2004 corresponds to special scheduling of the observation time, set to monitor dynamics in the northern summer mesosphere associated with the study of noctilucent clouds (Karlsson et al., 2004).

The time series shown in Fig. 8 gives an overview of the new $\mathrm{CO}$ dataset, extended to cover the whole globe including the polar regions. They consist of monthly zonal means of $\mathrm{CO}$ volume mixing ratios over five different latitude bands. The white bands correspond to months during which the number of scans in the given latitude band is lower than 10 . No concentrations are shown for some months in the early years of the mission, despite the presence of sufficient L2 data, because of plotting interpolation with adjacent months with no data (see Fig. 7). No significant difference between the various FMs is observed (not shown). CO volume mixing ratios show noticeable variations with altitude, latitude and season, as well as longer-term variations. We observe a sharp increase with height, due to the photodissociation of $\mathrm{CO}_{2}$ at high altitudes, as explained in Sect. 1. In these plots, it is also possible to notice the temporal variation of $\mathrm{CO}$ in the mesosphere throughout the years. In the tropics, maxima appear at equinoxes and minima at solstices. This is explained by the semiannual oscillation (SAO) signal, which dominates at low latitudes (Lee et al., 2018). Although the SAO-induced variations in zonal mean vertical wind are too small to be 


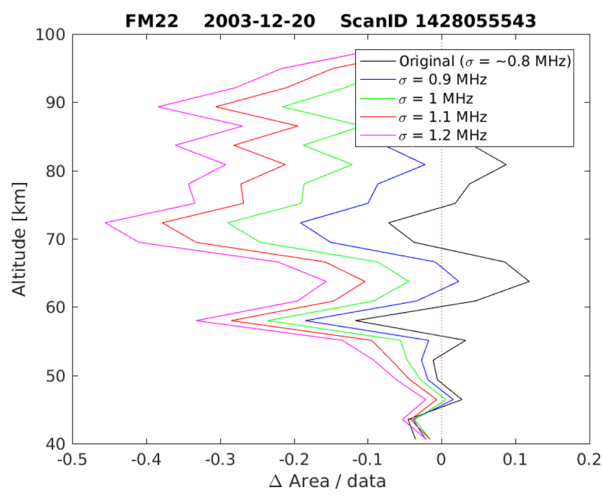

(a)

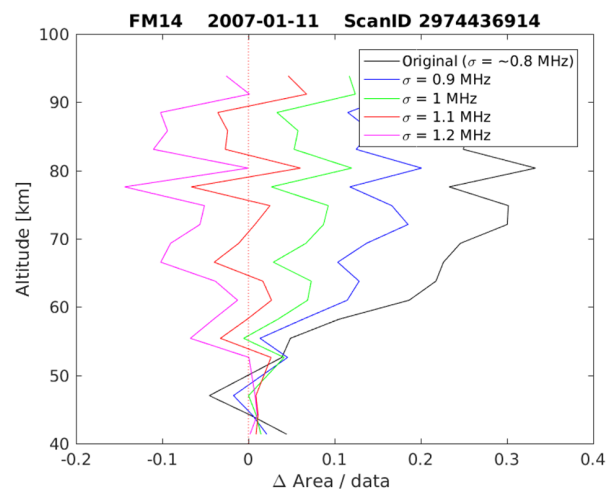

(b)

Figure 6. Relative difference between the Gaussian area beneath the observed CO line and the Gaussian area beneath the fit, obtained with different response functions for a scan in the PLL working period (a) and non-working period (b). The best response functions for the two cases are, respectively, the original one (black line) and the one with $\sigma=1.1 \mathrm{MHz}$ (red line).
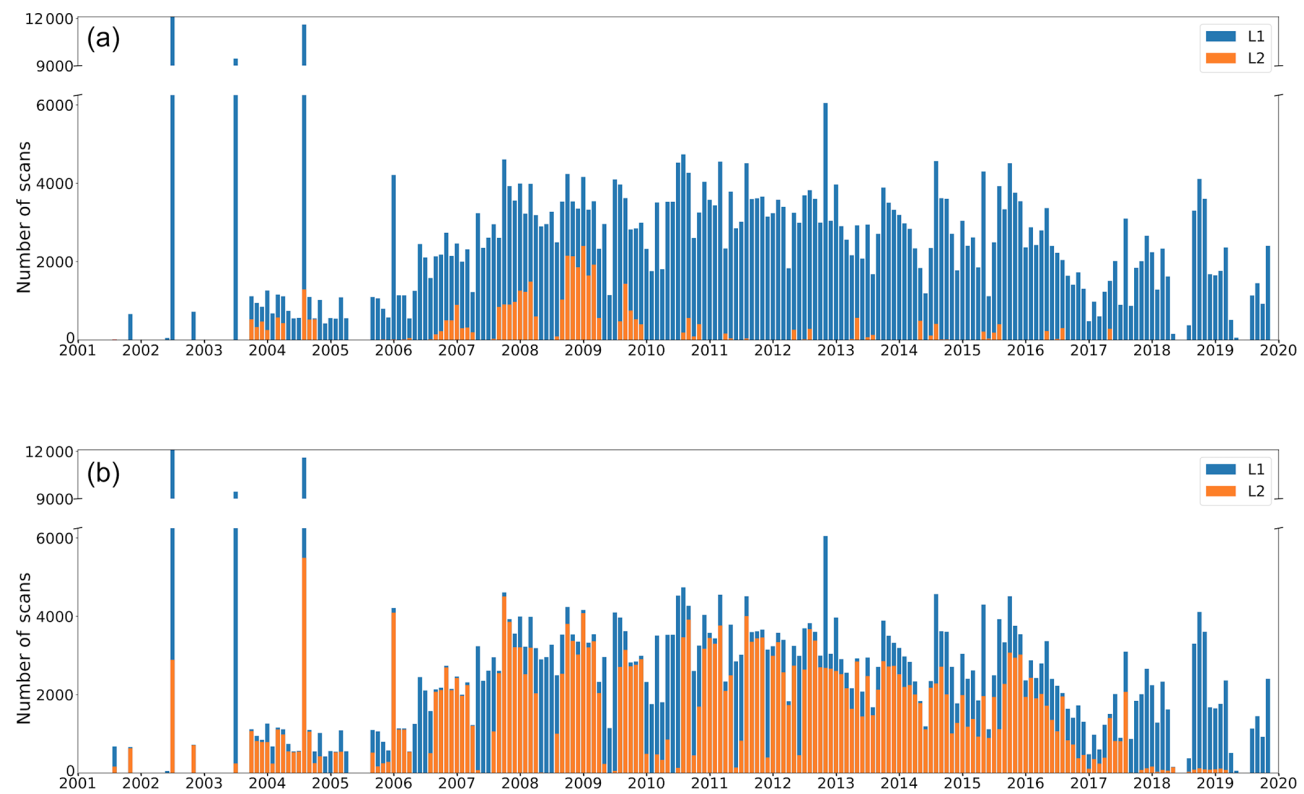

Figure 7. Number of L1 and L2 scans by month for FM14, FM22 and FM24 altogether, before (a) and after (b) the application of the correction algorithm. The ticks on the $x$ axis correspond to 1 January for each year. This figure gives an overview of how much data could be recovered.

measured directly, the accumulated effects can be seen in the distribution of the long-lived constituents like CO (Hamilton, 2005). Sinking of air, or at least anomalously weak rising motion, leads to the observed increase in the $\mathrm{CO}$ mixing ratios around the equinoxes. At high latitudes, the seasonal variations are mainly characterised by the downward transport of CO-rich air in winter, from the upper mesosphere to the stratopause, induced by the meridional circulation. The $\mathrm{CO}$ volume mixing ratio values measured in summer are lower, due to upward circulation. The SAO signal is noticeable at high latitudes too, explaining the secondary minima that are visible in the middle of the winter (Lee et al., 2018).
The seasonal variations at mid-latitudes are similar, though the effect of the meridional circulation is significantly less pronounced than at high latitudes. Moreover, at high latitudes in the Northern Hemisphere, a particularly strong secondary peak in $\mathrm{CO}$ concentration appears during several of the winters. This is observed in particular in 2006, 2009, 2013 and 2019. As seen in Fig. 8, unusually high volume mixing ratio values were measured in the mid- and lower mesosphere, in those years, in late winter. Such a pattern is generated by sudden stratospheric warming (SSW) events followed by an elevated stratopause event. SSWs occur almost entirely in the Northern Hemisphere, during wintertime, and consist 
of warmings of the stratosphere at high latitudes by several tens of kelvins, occurring within a few days. This is caused by planetary waves disturbing the polar vortex (e.g. Charlton and Polvani, 2007), thus reducing the descent of CO-rich air from higher altitudes. After such an event, the vortex recovers, and the stratopause sometimes reforms at higher altitudes than normal (Vignon and Mitchell, 2015), as it has already been observed by Odin/SMR (Pérot et al., 2014). In such a case, the downward-transported air will come from higher altitudes (Orsolini et al., 2017), where CO is more abundant, resulting in the above-mentioned higher concentration peak in late winter (Manney et al., 2009). Finally, it can be seen that, in all latitude bands, concentrations are in general higher during the period 2012-2016, in accordance with corresponding more intense solar activity. The described temporal variations are consistent with observations from other satellite instruments, such as MLS (Lee et al., 2018) and MIPAS (Funke et al., 2009; Garcia et al., 2014).

\section{Comparison with other instruments}

In this section we compare the SMR v3.0 CO dataset with data from other limb sounding satellite-borne instruments, namely MIPAS, ACE-FTS and MLS, and with ground-based measurements made by a radiometer located at the Onsala Space Observatory (OSO). Our goal is to assess the quality of the new dataset described above. With regards to satellite measurements, the comparison is performed between measurements that occurred within a maximum temporal separation of $24 \mathrm{~h}$ and a maximum spatial separation of $500 \mathrm{~km}$. It is possible to use such broad coincidence criteria because of CO's long chemical lifetime in the mesosphere (Minschwaner et al., 2010). CO in the mesosphere and lower thermosphere (MLT) is affected by tidal mixing (Garcia et al., 2014), which might contribute to the biases observed in comparisons with such a broad temporal coincidence criterion. To investigate if this is the case, we also carried out comparisons with 3 and $6 \mathrm{~h}$ coincidence criteria. When not characterised by the absence of sufficient coincidences (i.e. less than 10), these comparisons do not present biases which are significantly different from the $24 \mathrm{~h}$ ones. No plot is shown for the 3 and $6 \mathrm{~h}$ comparisons. All the validation plots shown hereafter refer to $24 \mathrm{~h}$ coincidences.

$\mathrm{CO}$ vertical concentration profiles do not feature particular structures which would justify taking into account the satellite instruments' different vertical resolutions, also considering that such differences are not as marked as the ones between SMR and OSO (coincidence criteria and smoothing process for the SMR-OSO comparison are presented in Sect. 5.4). The comparison between space-borne instruments has therefore been performed simply by linearly interpolating each coincident profile over a common $1 \mathrm{~km}$ altitude grid, ranging from 50 to $100 \mathrm{~km}$. Given a couple of coincident measurements denoted with $i$, the absolute difference of the two at altitude $z$ will be given by

$\delta_{\mathrm{abs}, i}(z)=x_{\mathrm{SMR}}-x_{\mathrm{comp}}$

and the relative difference

$\delta_{\text {rel }, i}(z)=\frac{x_{\text {SMR }}-x_{\text {comp }}}{\left(x_{\text {SMR }}+x_{\text {comp }}\right) / 2}$,

where $x_{\mathrm{SMR}}$ and $x_{\text {comp }}$ are respectively the CO mixing ratios measured from SMR and the comparison instrument at altitude $z$ for the coincidence $i$. The relative difference has as its denominator the mean of the two concentrations. This is done because, being both satellite measurements, they can both be affected by large uncertainties and none of the two is preferable as a reference (Randall et al., 2003). To minimise the weight of outliers, the median difference $\Delta(z)$ over all the $N(z)$ coincidences at altitude $z$ is calculated. The dispersion of the results is represented by the standard deviation of the median, calculated as follows:

$\operatorname{SEM}(z)=\frac{1}{\sqrt{N(z)}} \sqrt{\frac{1}{N(z)-1} \sum_{i=1}^{N(z)}\left(\delta_{i}(z)-\Delta(z)\right)^{2}}$.

This is valid for both absolute and relative difference. The average and standard error of the concentration profiles are calculated using the same method. For the sake of clarity, in the following subsections we only show vertical profiles averaged over all the found coincidences, regardless of time or location. However, figures showing the relative differences between SMR and the other limb sounders as a function of altitude and latitude, for each season, have been included in the appendix and will be regularly referred to throughout the text.

\subsection{MIPAS}

The Michelson Interferometer for Passive Atmospheric Sounding (MIPAS) is a mid-infrared spectrometer which was launched on board Envisat on 1 March 2002 and was operating until April 2012, when an unexpected loss of contact with the satellite occurred. The satellite travelled at $800 \mathrm{~km}$ altitude on a sun-synchronous orbit with a $98.55^{\circ}$ inclination and a 22:00 LT ascending node. The concentration profiles that we use for comparison in this study are retrieved from measurements of ${ }^{12} \mathrm{C}^{16} \mathrm{O}$ roto-vibrational emissions in the $v=1 \rightarrow 0$ band around $4.7 \mu \mathrm{m}$, using the retrieving processor developed at the Institute of Meteorology and Climate Research (IMK) in Karlsruhe and the Instituto de Astrofisica de Andalucia (IAA) in Granada (e.g. Funke et al., 2009; Sheese et al., 2016). The forward model used for CO retrieval takes into account non-LTE effects. We consider data from the most recent MIPAS datasets, as specified in Table 2 (Garcia et al., 2014, 2016). All recommendations about the quality filtering of the data have been followed (Kiefer and Lossow, 2017). 

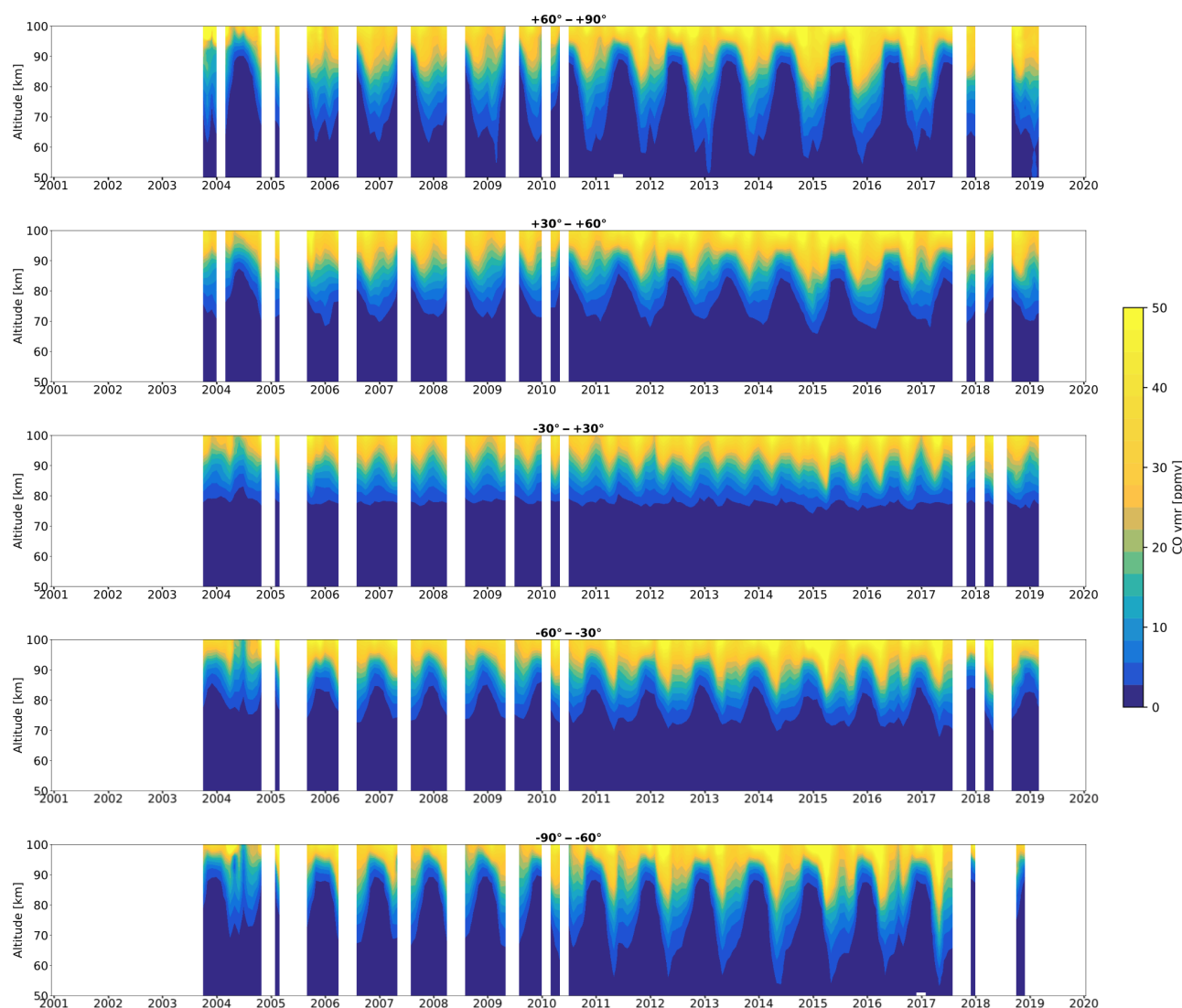

Figure 8. Time series of CO volume mixing ratios measured by SMR for different latitude bands. The white bands indicate periods during which the number of scans in the given latitude band is lower than 10. The ticks on the $x$ axis correspond to the beginning of each year.

Table 2. Characteristics of the MIPAS CO datasets used for comparison. Vertical resolutions refer to the observations in the altitude range $50-100 \mathrm{~km}$ considered in this study.

\begin{tabular}{|c|c|c|c|c|c|}
\hline Observation mode & Altitude range & Vertical resolution & Spectral resolution mode & Time period & Version \\
\hline \multirow{2}{*}{ Nominal (NOM) } & \multirow{2}{*}{$10-70 \mathrm{~km}$} & $5-15 \mathrm{~km}$ & Full resolution (FR) & $\begin{array}{l}\text { July } 2002 \rightarrow \\
\text { March } 2004\end{array}$ & V5H_CO_20 \\
\hline & & $6-16 \mathrm{~km}$ & \multirow{3}{*}{$\begin{array}{l}\text { Optimised } \\
\text { resolution (OR) }\end{array}$} & \multirow{3}{*}{$\begin{array}{l}\text { January } 2005 \rightarrow \\
\text { April } 2012\end{array}$} & V5R_CO_220 \\
\hline Middle atmosphere (MA) & $20-100 \mathrm{~km}$ & $5-15 \mathrm{~km}$ & & & V5R_CO_521 \\
\hline Upper atmosphere (UA) & $42-150 \mathrm{~km}$ & $5-12 \mathrm{~km}$ & & & V5R_CO_621 \\
\hline
\end{tabular}

\subsubsection{Nominal mode}

There are two observation modes called "nominal": one in use during the period before the interferometer in MIPAS started malfunctioning, when the instrument was being used in full spectral resolution (FR mission); and one in use after the instrument was recovered and brought back to function with a reduced spectral resolution (OR mission) (Oelhaf, 2008).

Regarding the FR-NOM mode, with the above-mentioned coincidence criteria we found 6088 coincident measurements with SMR over the period July 2002-March 2004. The pro- files and differences between 50 and $70 \mathrm{~km}$ altitude, averaged over the whole time period and over the whole globe, are shown in Fig. 9a. The median relative difference between SMR and MIPAS has a value of $+8 \%$ at $50 \mathrm{~km}$ which decreases to reach $-15 \%$ at $60 \mathrm{~km}$ and eventually remains constant between 60 and $70 \mathrm{~km}$ altitude. No bias characterising a particular latitude or season over time has been identified for this specific comparison, since FR-NOM mode has been operational for only a short period.

Comparing with OR-NOM mode, 88902 coincident measurements have been found over the period January 2005 April 2012. Figure $9 \mathrm{~b}$ shows that the median relative dif- 
ference between SMR and MIPAS remains positive and almost constant with altitude, staying below $+15 \%$. The main contribution to this difference comes from latitudes between -25 and $+50^{\circ}$ - in particular during northern summer, around $+25^{\circ}$, where it reaches values above $+40 \%$ between 65 and $70 \mathrm{~km}$. Everywhere else relative difference values remain within $\pm 20 \%$ (see Fig. A1). To check if the observed differences are due to differences in vertical resolutions between the two instruments, we compared SMR and MIPAS profiles separately for daytime and nighttime observations. In fact, MIPAS vertical resolutions are similar to SMR's for daytime observations, while they are equal to more than $10 \mathrm{~km}$ for nighttime observations, due to lower sensitivity caused by smaller non-LTE emissions (Funke et al., 2009). The average comparison between daytime observations did not show differences that deviate significantly from the ones observed in Fig. 9 (not shown). This suggests that the observed concentration differences are not due to differences in vertical resolution.

\subsubsection{Middle atmosphere mode}

Another observation mode in use during the OR mission is the middle atmosphere mode, covering a larger altitude range. Its average comparison with SMR over 17003 coincidences is shown in Fig. 9c. Both datasets are in general in good agreement with each other. It can be seen that the average difference always stays between $-20 \%$ and $+20 \%$. In particular, SMR presents a positive difference of around $+20 \%$ at $50 \mathrm{~km}$ which decreases with altitude until it becomes null at $60 \mathrm{~km}$. The difference keeps being negligible up until $70 \mathrm{~km}$, and then it becomes negative and keeps decreasing until it reaches a minimum of $-20 \%$ around $85 \mathrm{~km}$, after which it goes back up to $+5 \%$ at $100 \mathrm{~km}$. The observed difference around $85 \mathrm{~km}$ is not to be attributed to MIPAS misestimation of non-LTE effects; in fact non-LTE modelling of MIPAS CO has been validated in Funke et al. (2007) and systematic errors due to non-LTE were estimated to be less than $5 \%$. When looking at latitudes separately, the relative differences are mainly within $\pm 20 \%$. The most extreme differences are observed around the northern spring equinox. Here we have very negative differences at the Equator between 70 and $80 \mathrm{~km}$ altitude reaching peaks of $-60 \%$. Differences of $-50 \%$ can be observed during local summer in both hemispheres at high latitudes between 80 and $90 \mathrm{~km}$. Also peaks of positive difference around $+60 \%$ are reached at $50 \mathrm{~km}$ altitude at -75 and $+50^{\circ}$ (see Fig. A2). Considerations about daytime and nighttime comparisons carried out separately are the same as in Sect. 5.1.1.

\subsubsection{Upper atmosphere mode}

Figure 9d shows the comparison with OR upper atmosphere mode, averaged over 19084 coincidences. The SMR difference in comparison with this mode is very similar to the one described in Sect. 5.1.2. A small dissimilarity is given at higher altitudes where the difference approaches zero but stays negative. Moreover, as described in Sect. 5.1.2, observed differences around $85 \mathrm{~km}$ are thought not to be caused by MIPAS misestimation of non-LTE effects. At all latitudes and during all seasons, relative difference values are small and generally within $\pm 20 \%$. Peaks of almost $-50 \%$ are reached during the northern spring at the Equator between 70 and $80 \mathrm{~km}$ and during local summer in both hemispheres at high latitudes between 80 and $90 \mathrm{~km}$ (see Fig. A3). Considerations about daytime and nighttime comparisons carried out separately are the same as in Sect. 5.1.1.

\subsection{ACE-FTS}

The Fourier Transform Spectrometer (FTS) is an instrument which is part of the Canadian-led Atmospheric Chemistry Experiment (ACE) on board SCISAT-1, launched on $12 \mathrm{Au}-$ gust 2003 (and still operating) into a $74^{\circ}$ inclination orbit at $650 \mathrm{~km}$ altitude (Bernath et al., 2005). ACE-FTS performs solar occultation measurements in the mid-infrared. In particular, $\mathrm{CO}$ concentrations are retrieved from the rotovibrational absorption bands around $4.7 \mu \mathrm{m}(v=1 \rightarrow 0)$ and $2.3 \mu \mathrm{m}(v=2 \rightarrow 0)$. CO retrievals are performed between 5 and $105 \mathrm{~km}$ altitude, with a $3-4 \mathrm{~km}$ vertical resolution (Boone et al., 2005, 2013). In this study we use ACE-FTS v3.6 dataset for comparison. The data have been quality filtered according to the guidelines from the instrument team (Sheese et al., 2015).

A total of 12925 coincident $\mathrm{CO}$ measurements between ACE-FTS and SMR were found between February 2004 (first available ACE-FTS CO measurements) and March 2019. The number of coincidences found is lower compared with any of the MIPAS modes, despite the longer period considered. This is due to the fact that ACE-FTS is a solar occultation instrument, thus scanning the limb only twice per orbit, while both SMR and MIPAS are measuring almost continuously. The spatial and temporal average comparison with ACE-FTS is shown in Fig. 10. The relative difference decreases almost monotonically with altitude, from a maximum of $+15 \%$ at $50 \mathrm{~km}$ to a minimum of almost $-15 \%$ at the highest altitudes. In particular, the difference decreases more quickly between 50 and $60 \mathrm{~km}$ from $15 \%$ to near $0 \%$. SMR and ACE-FTS are in extremely good agreement with each other between 60 and $75 \mathrm{~km}$, with a relative difference close to zero. The difference then slowly decreases with altitude up to about $-15 \%$ at $90 \mathrm{~km}$ and finally increases almost imperceptibly between 90 and $100 \mathrm{~km}$. Looking at seasons separately, the relative differences present generally low values, almost always within $\pm 20 \%$. Values only increase to more than $+40 \%$ between 60 and $70 \mathrm{~km}$ during northern autumn around $+25^{\circ}$ and during southern winter at the Equator and around $-25^{\circ}$. The latter difference is similar to the one observed from ACE with respect to MIPAS (Sheese et al., 2016). Moreover, strong negative differences of about $-40 \%$ 


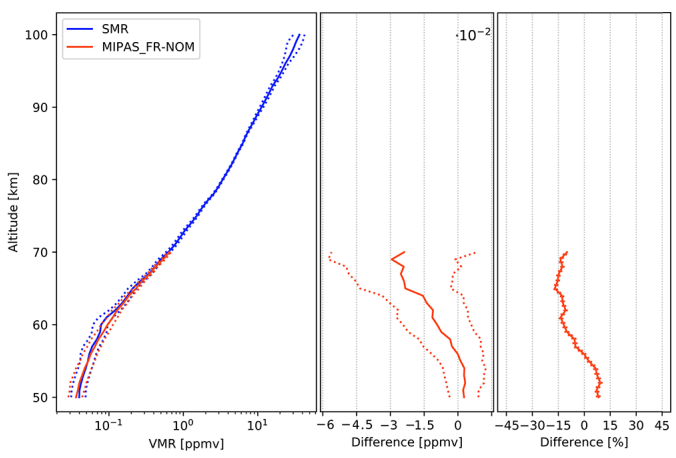

(a)

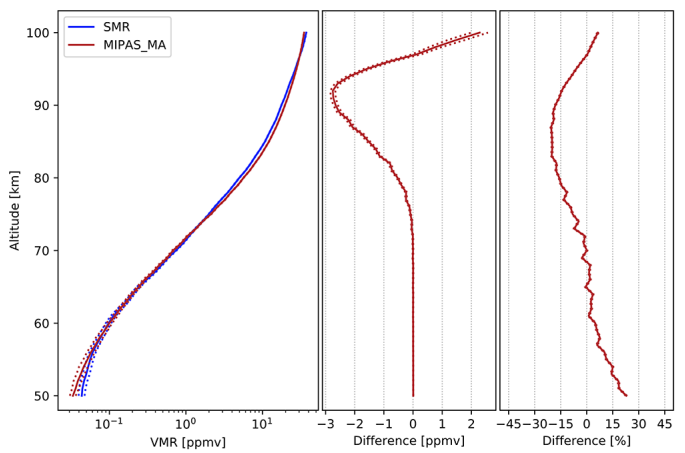

(c)

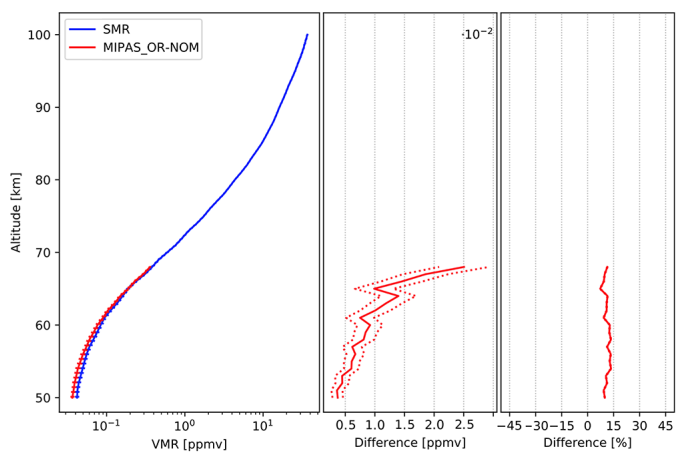

(b)

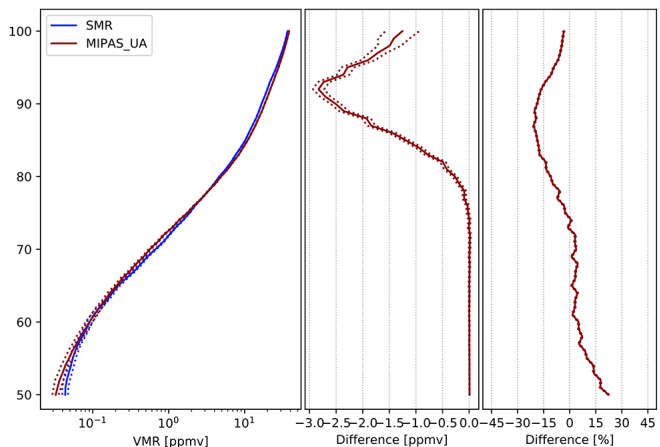

(d)

Figure 9. Comparison of SMR CO concentrations with the ones from MIPAS FR-nominal (a), OR-nominal (b), middle atmosphere (c) and upper atmosphere (d) modes. The data plotted are global averages over the whole time periods indicated in Table 2. (Left subpanels) Volume mixing ratios, expressed in parts per million by volume (ppmv). (Center subpanels) Absolute differences, expressed in ppmv. (Right subpanels) Relative differences, expressed in percentage. The dashed lines represent the standard deviation of the median which, in some cases, is smaller than the thickness of the profile line, causing the dashed line not to be distinguishable.

are observed at the Equator at $80 \mathrm{~km}$ altitude during northern spring and also at $+25^{\circ}$ during northern autumn between 80 and $90 \mathrm{~km}$ (see Fig. A4). Note that the majority of ACE-FTS measurements occur at latitudes higher than $60^{\circ}$ and that the above-mentioned differences at low latitudes are probably related to averaging on a smaller number of coincidences.

\subsection{MLS}

The Microwave Limb Sounder (MLS) is an instrument on board the Aura satellite, still operating since its launch on 15 July 2004. Aura/MLS was launched on a $98^{\circ}$ sunsynchronous orbit with 13:45 LT ascending node at an altitude of $705 \mathrm{~km}$. It performs measurements between $118 \mathrm{GHz}$ and $2.5 \mathrm{THz}$ with a $1.5-3 \mathrm{~km}$ vertical resolution (Schoeberl et al., 2006; Waters et al., 2004). In this study we use MLS $\mathrm{CO}$ concentrations from the $\mathrm{v} 4$ dataset, retrieved from the $J=2 \rightarrow 1$ rotational transition emission line at $230.5 \mathrm{GHz}$, which are considered to be reliable between 0.0046 and $215 \mathrm{hPa}$. Also, the suggested quality filtering has been performed (Livesey et al., 2018). A previous comparison between SMR and MLS CO retrievals was presented in Barret et al. (2006), based on older versions of the datasets. A validation study of the MLS CO v2 dataset has been performed by Pumphrey et al. (2007), and the differences between v2 and v4 datasets are documented in Livesey et al. (2018).

Because MLS uses the same observation technique as SMR, and because it has been functioning since 2004, a great number of coincident measurements could be used for this validation study. Indeed, 227820 coincidences were found between the beginning of MLS mission and March 2019. The overall average comparison of these measurements with the ones from SMR is shown in Fig. 11. A negative difference of SMR with respect to MLS characterises all of the altitude range. The relative differences are oscillating between $-40 \%$ and $-10 \%$ and are characterised by a significant variability. This is due to MLS CO profiles being rather jagged, as reported in Errera et al. (2019), where the MLS bias described is in accordance with what we obtain in this study. Also, the MLS-ACE bias which is reported in Sheese et al. (2016) - although referring to older versions of the two datasets - is consistent with the one we measure. The difference we measure varies significantly with latitudes and seasons: between -40 and $+40^{\circ}$ and below $70 \mathrm{~km}$, there are peaks of $-150 \%$ and $-80 \%$ during northern spring and autumn, respectively; while marked negative differences are registered during local summertime in 


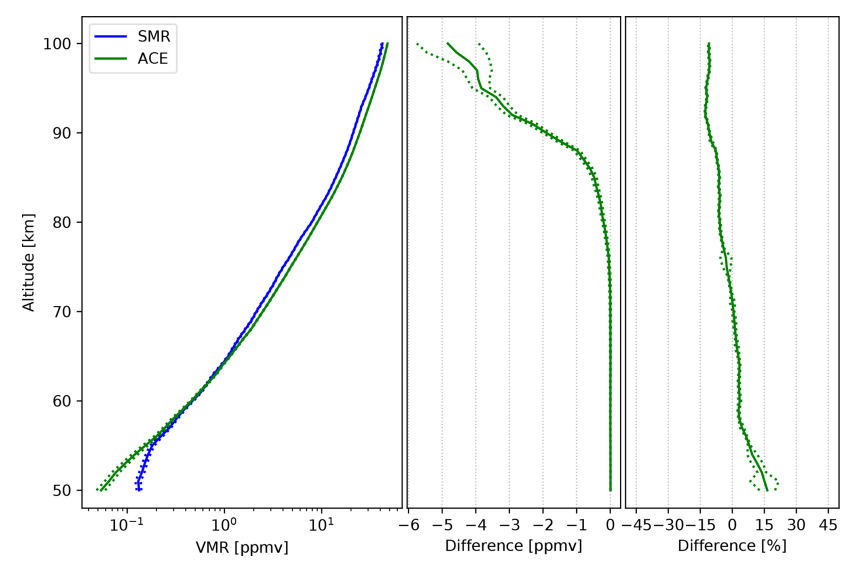

Figure 10. Comparison of SMR CO concentrations with the ones from ACE-FTS retrievals. The data plotted are global averages over the whole time between February 2004 and March 2019. Panels characteristics are the same as in Fig. 9.

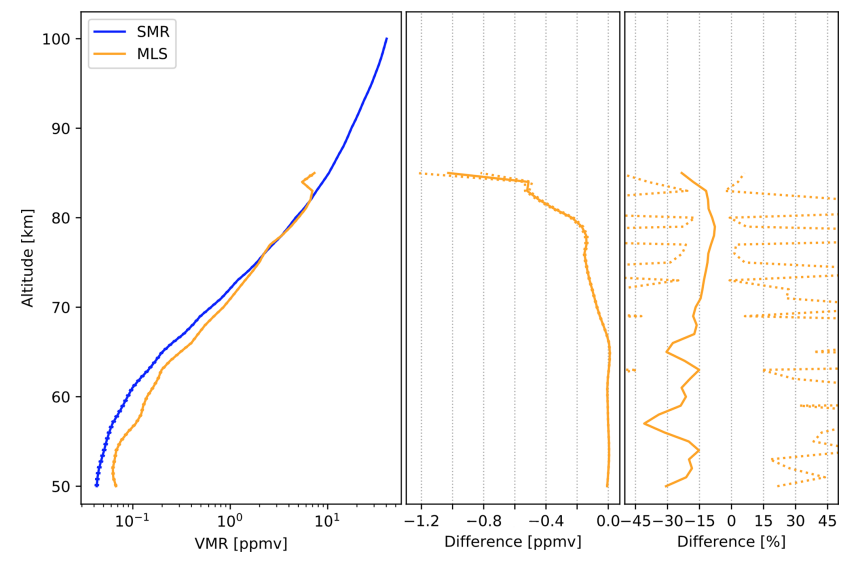

Figure 11. Comparison of SMR CO concentrations with the ones from MLS observations. The data plotted are global averages over the whole time between July 2004 and March 2019. Panels characteristics are the same as in Fig. 9.

both hemispheres, getting more pronounced toward high latitudes, especially around 50 and $70 \mathrm{~km}$ altitude with peaks of $-120 \%$, as shown in Fig. A5 (this is also observed in the ACE-MLS comparison in Sheese et al., 2016).

\subsection{OSO}

Odin/SMR CO data are compared with data measured by a ground-based remote-sensing instrument at the Onsala Space Observatory, OSO $\left(57.4^{\circ} \mathrm{N}, 11.9^{\circ} \mathrm{E}\right)$, during 2002-2007. The recommended quality filtering has been followed.

The OSO instrument is a frequency-switched microwave radiometer for observations of the $\mathrm{CO} 1 \rightarrow 0$ transition at 115.27 GHz. During 2002-2007, a cooled Schottky single sideband mixer was used as the first stage. In 2014 the instrument was modified to a double-sideband system with a

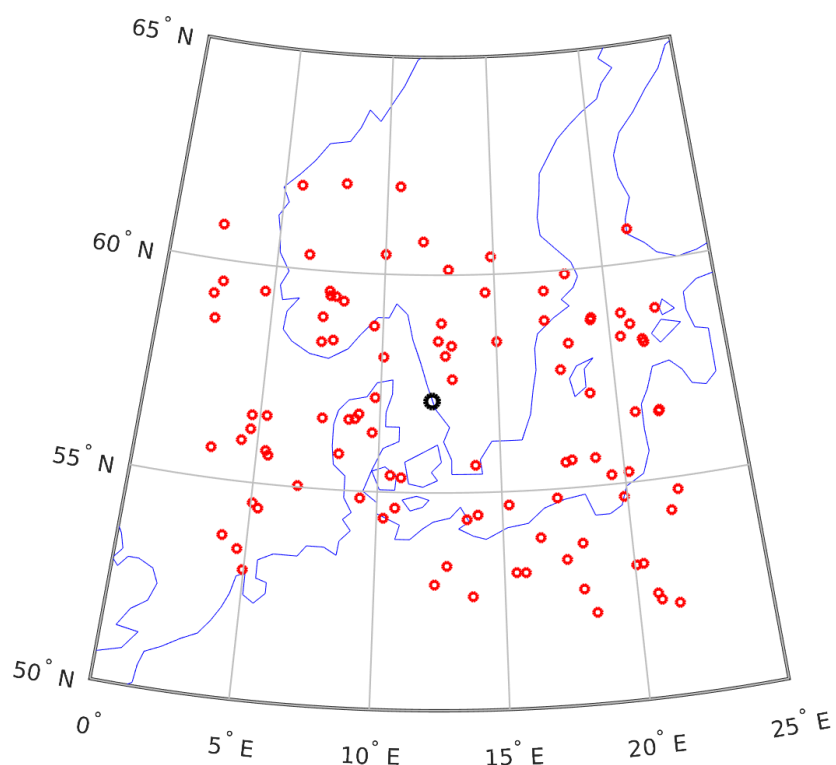

Figure 12. Odin/SMR-OSO coincidences. Red circles show the 89 coincidences during 2002-2007 and the black circle shows the OSO site.

low-noise amplifier, at ambient temperature, as the first stage. During 2002-2007 a spectrometer with $20 \mathrm{MHz}$ bandwidth and a resolution of $25 \mathrm{kHz}$ was used. The optimal estimation method together with the forward model ARTS, the Atmospheric Radiative Transfer Simulator (Eriksson et al., 2011), has been used to retrieve vertical CO profiles from the measured spectra. The OSO instrument, the calibration and retrieval methods are described in Forkman et al. (2012, 2016).

Daily averages for 2002-2007 of CO profiles are retrieved from the OSO spectra. Only the $24 \mathrm{~h}$ average $\mathrm{CO}$ spectra with a signal-to-noise ratio larger than 2 are used in the retrievals. SMR data are regarded as coincident with OSO if the differences in latitude and longitude do not exceed \pm 5 and $\pm 10^{\circ}$ respectively and if the SMR data are taken within the OSO time average periods mentioned above. For the period 2002 2007, there are 89 coincident SMR profiles ( see Fig. 12).

Figure 13 shows the mean vertical CO profiles for the coincident SMR and OSO datasets. The limb sounding SMR has a much higher vertical resolution than the upwardlooking OSO instrument. To compensate for this difference, the SMR profiles, $x_{\text {sat }}$, were convoluted with the averaging kernels, $A$, of the OSO instrument (Rodgers, 2000).

$x_{\mathrm{s}}=x_{\mathrm{a}}+A\left(x_{\mathrm{sat}}-x_{\mathrm{a}}\right)$,

where $x_{\mathrm{a}}$ is the OSO a priori and $x_{\mathrm{s}}$ the smoothed SMR profile. The measurement response of SMR is very close to 1 in the $50-100 \mathrm{~km}$ range. The altitude range in Fig. 13 is more narrow since it is given by the range where the measurement response of the OSO instrument is $>0.75$.

OSO data from 2002-2007 have been compared to data from the satellite instruments ACE-FTS, MIPAS and MLS in 

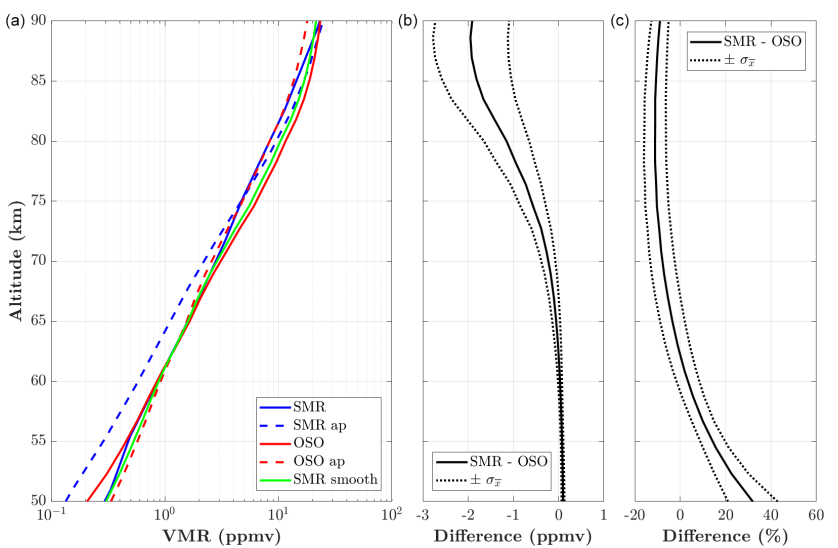

Figure 13. SMR-OSO comparison for 2002-2007. (a) Blue solid/dashed are the average SMR retrieved/a priori profiles, red solid/dashed are the average OSO retrieved/a priori profiles and green is the smoothed SMR profile. $(\mathbf{b}, \mathbf{c})$ The average difference between the smoothed SMR and OSO profiles, solid, together with the standard error of the mean, $\sigma_{\bar{x}}$, dotted, is shown in parts per million by volume and percent, respectively.

a previous study (Forkman et al., 2012). As seen in Fig. 13, during this period, the difference between SMR data and the coincident averaged data from OSO was found to be of $30 \%$ at $50 \mathrm{~km}$, decreasing with altitude to reach $-10 \%$ at $60 \mathrm{~km}$ and remaining constant up until $90 \mathrm{~km}$ altitude. The standard error of the mean, $\sigma_{\bar{x}}$, for the average difference between SMR and OSO is about $5 \%$ above $55 \mathrm{~km}$ (see Fig. 13).

\section{Conclusions}

Before the application of the corrections described in this study, almost the whole Odin/SMR CO dataset was unusable due to line shifts and broadening of instrumental origin, due to the phase-lock loop malfunctioning. Line displacement resulted in the failure of inversions or inaccurate retrievals, while the instrumental broadening caused underestimation of the concentration values. We estimated and corrected the different impacts of the PLL malfunctioning on SMR CO measurements. Line shifts were addressed by developing a correction algorithm which allowed the $\mathrm{CO}$ lines to be repositioned to their theoretical centre, also considering different frequency shifts for each tangent altitude within a scan. This resulted in the recovery of a great part of the dataset. Line broadening was taken into account using a broader response function for the retrievals. That led to a new, good-quality, Odin/SMR v3.0 mesospheric CO dataset, covering more than 18 years of observations. Time series of the retrieved volume mixing ratios reveal variations consistent with known mesospheric dynamical patterns, such as the annual cycle of the meridional circulation, SAO, and SSWs, as well as a clear 11-year solar cycle signal. The validation study shows, on average, a good agreement with both the

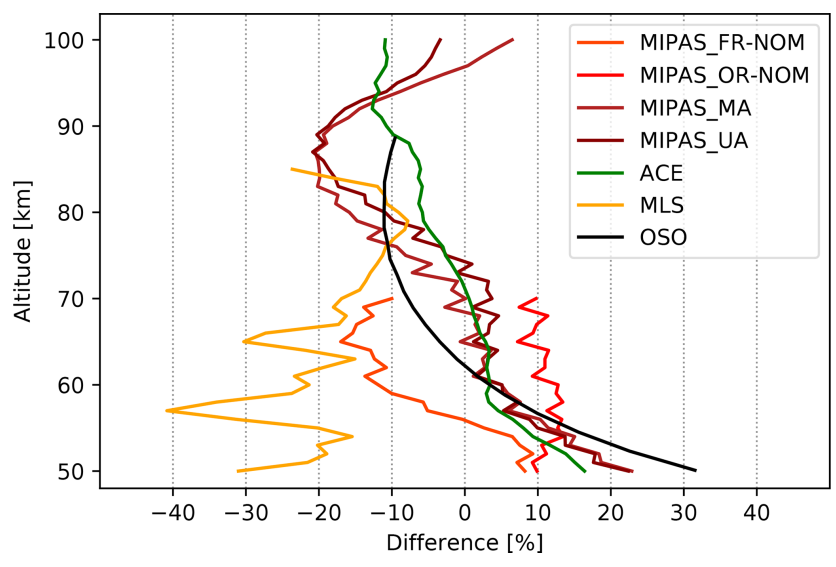

Figure 14. Summary of relative differences between SMR CO concentrations and the ones measured by all other instruments considered in this study. For the sake of clarity, errors are not shown.

ground-based radiometer OSO and the three satellite-borne instruments (MIPAS, ACE-FTS, MLS) considered for comparison (see Fig. 14). In particular, between 60 and $80 \mathrm{~km}$ SMR agrees very well with almost all instruments, presenting relative differences close to zero. Comparisons with MIPAS, ACE-FTS and OSO show a positive bias of SMR of up to $+20 \%$ at low altitudes $(50-60 \mathrm{~km})$ and a negative bias of up to $-20 \%$ at high altitudes $(80-100 \mathrm{~km})$. Something different is found with regards to MLS - i.e. negative difference at all altitudes, ranging from $-40 \%$ to $-10 \%-$ which is in accordance with the stated MLS bias (Errera et al., 2019).

To investigate if the reason for the observed differences is to be attributed to differences in vertical resolution, we smoothed SMR and comparison instrument profiles using Gaussian filters with various FWHMs. This test did not show any improvement in concentration differences (not shown), suggesting that differences in vertical resolution are not the cause of the observed biases. Other evidence for this, regarding comparisons with MIPAS modes, is given by the fact that comparisons of daytime measurements (which are characterised by similar vertical resolutions for SMR and MIPAS) do not show differences in concentration that vary from what is observed when comparing measurements all together. Moreover, systematic errors from non-LTE modelling in MIPAS measurements amount to less than $5 \%$ (Funke et al., 2007) and are therefore not thought to be the cause for the observed SMR-MIPAS differences at high altitudes. Thus, the causes for the observed concentration differences between SMR and the comparison instruments, both globally and for different latitudes and seasons, are unknown at the moment and require further investigation.

Given its unique extension in time and geographical coverage, this new mesospheric $\mathrm{CO}$ dataset provides a valuable tool for further studies of mesosphere dynamics. 


\section{Appendix A}
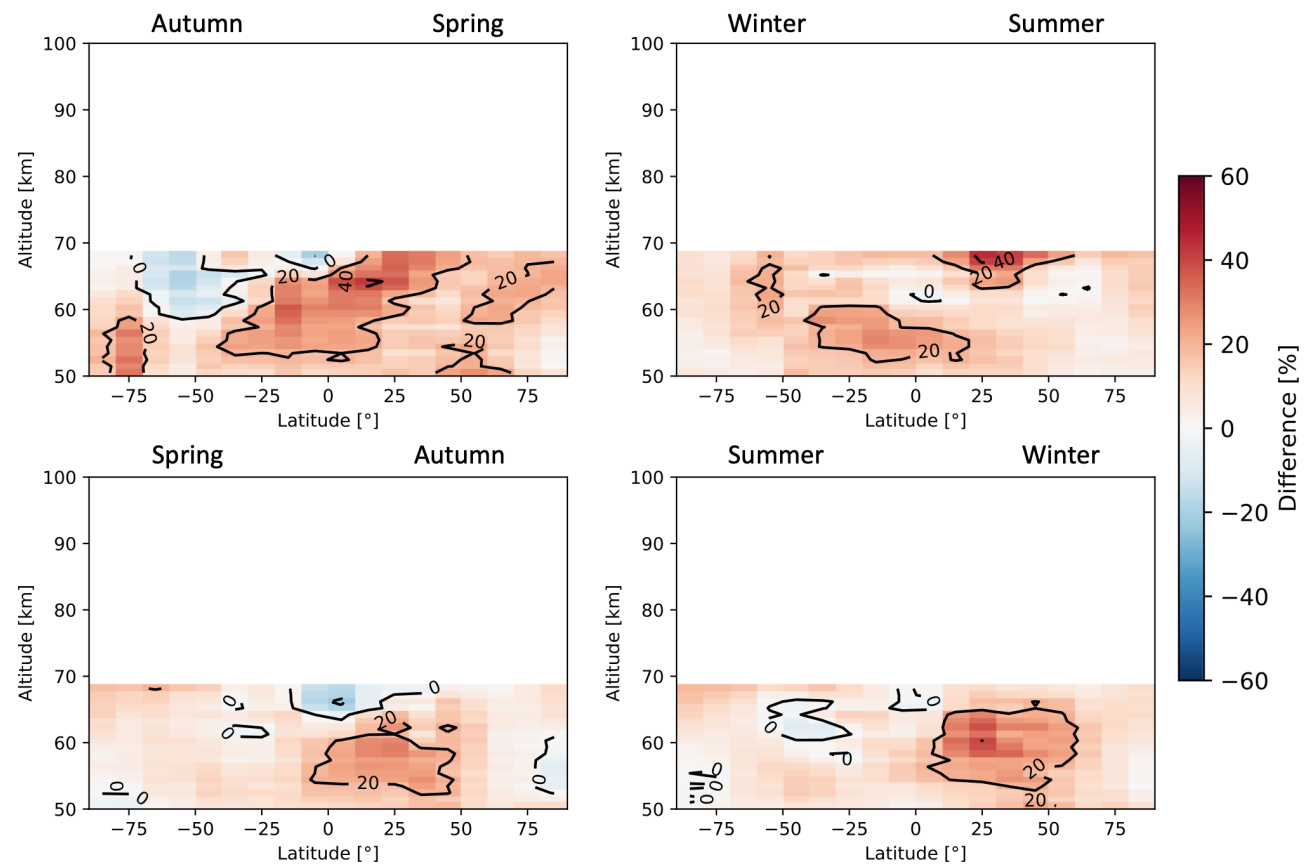

Figure A1. Seasonal zonal means of SMR-MIPAS OR-NOM relative differences averaged over the time period indicated in Table 2. The seasons are intended as the time between the solstice and the equinox.
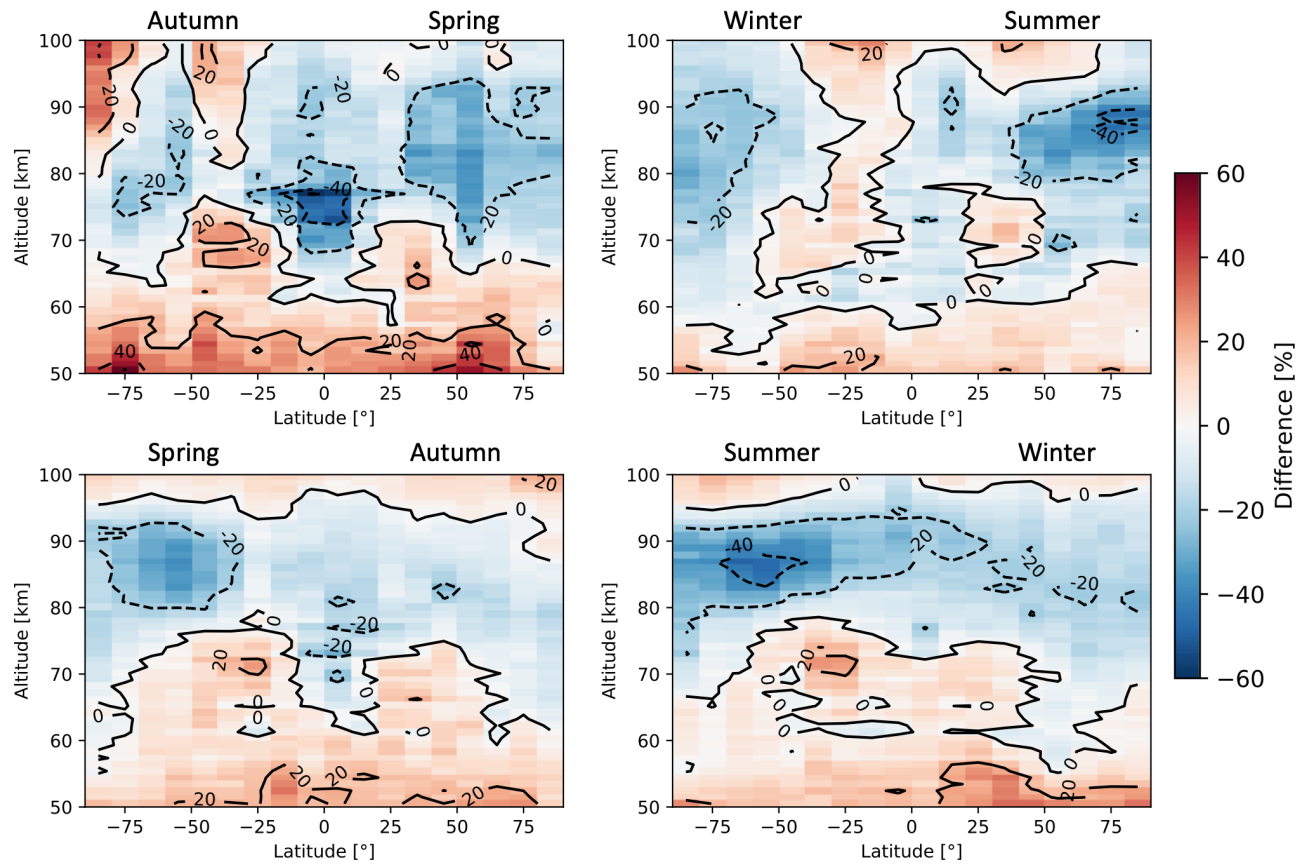

Figure A2. Seasonal zonal means of SMR-MIPAS middle atmosphere relative differences averaged over the time period indicated in Table 2. The seasons are intended as the time between the solstice and the equinox. 

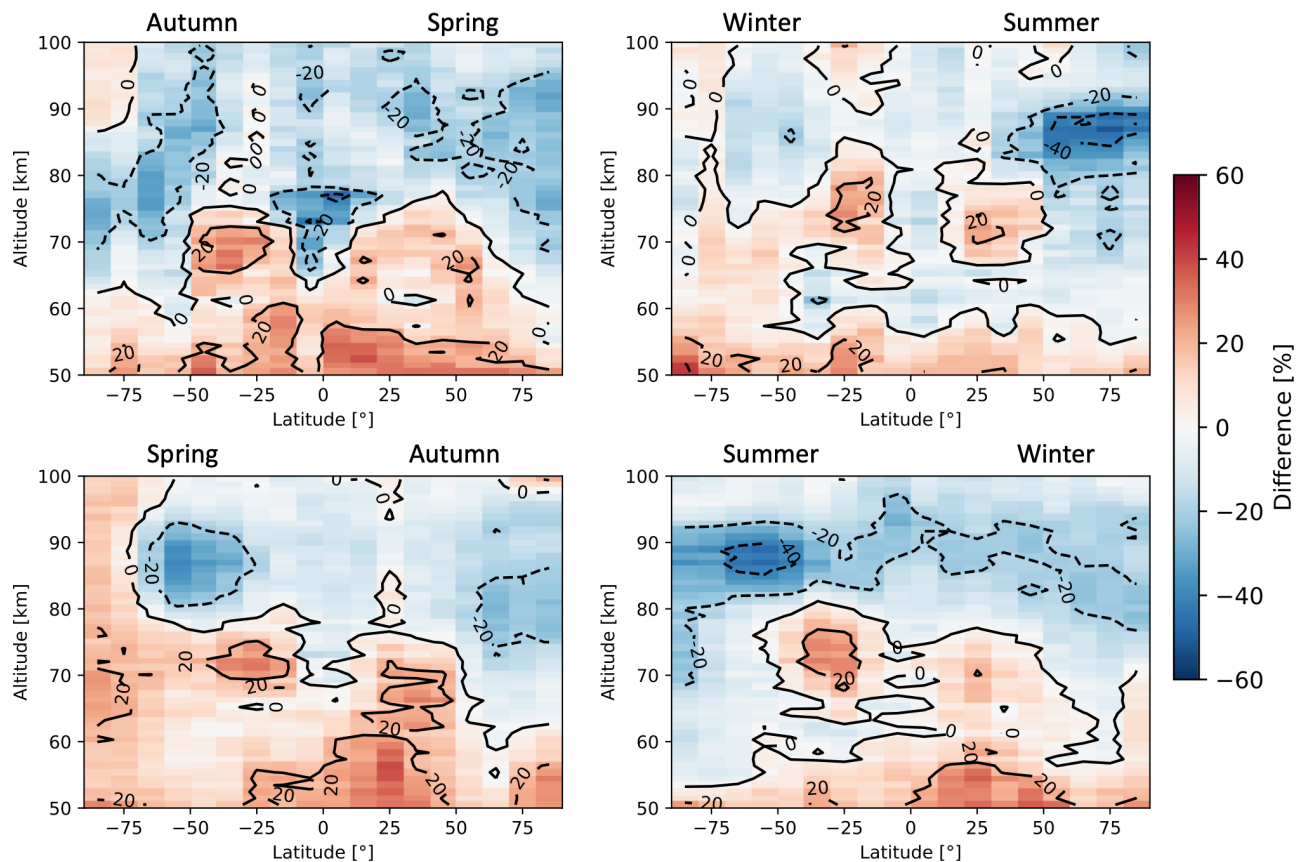

Figure A3. Seasonal zonal means of SMR-MIPAS upper atmosphere relative differences averaged over the time period indicated in Table 2. The seasons are intended as the time between the solstice and the equinox.
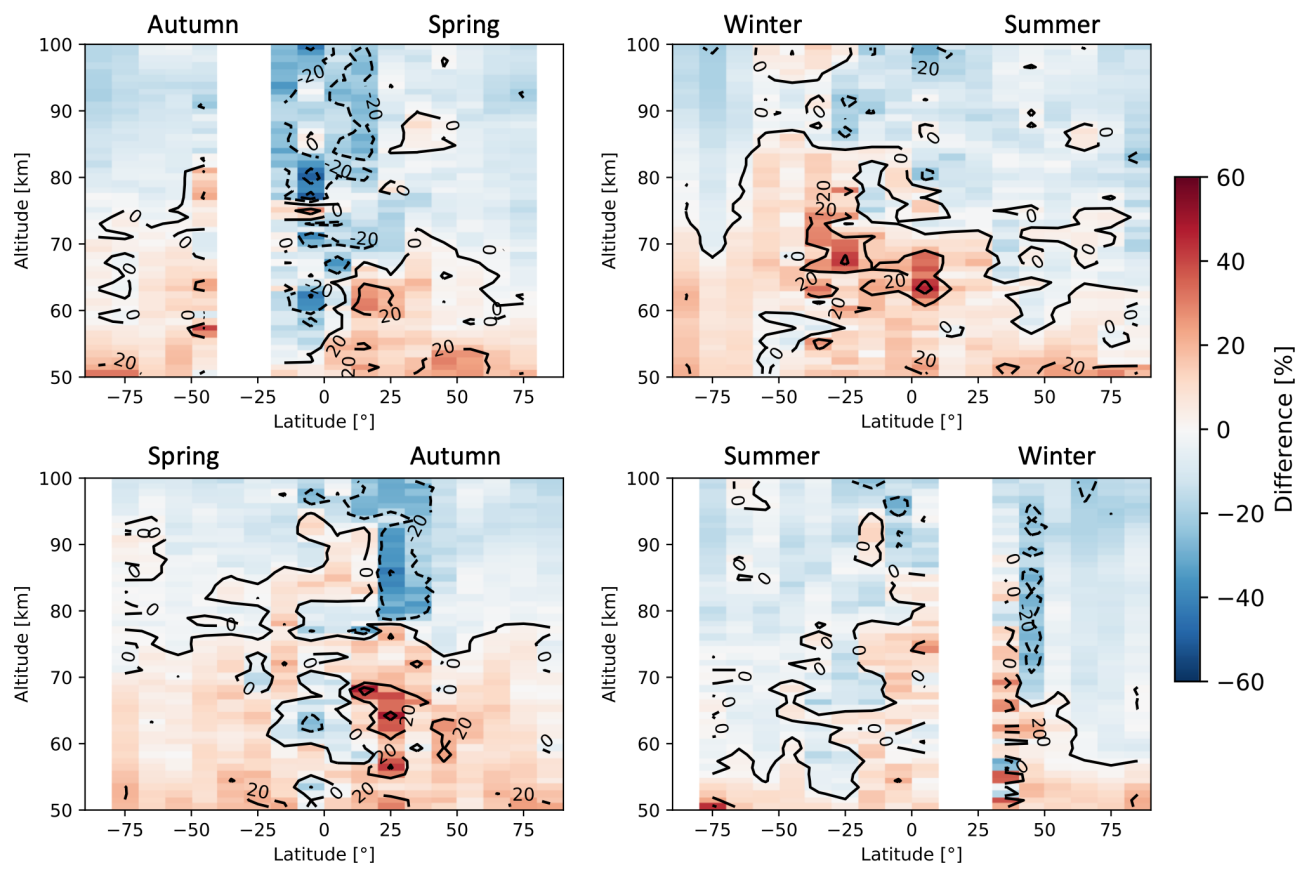

Figure A4. Seasonal zonal means of SMR-ACE relative differences averaged over the whole time between February 2004 and March 2019. The seasons are intended as the time between the solstice and the equinox. 

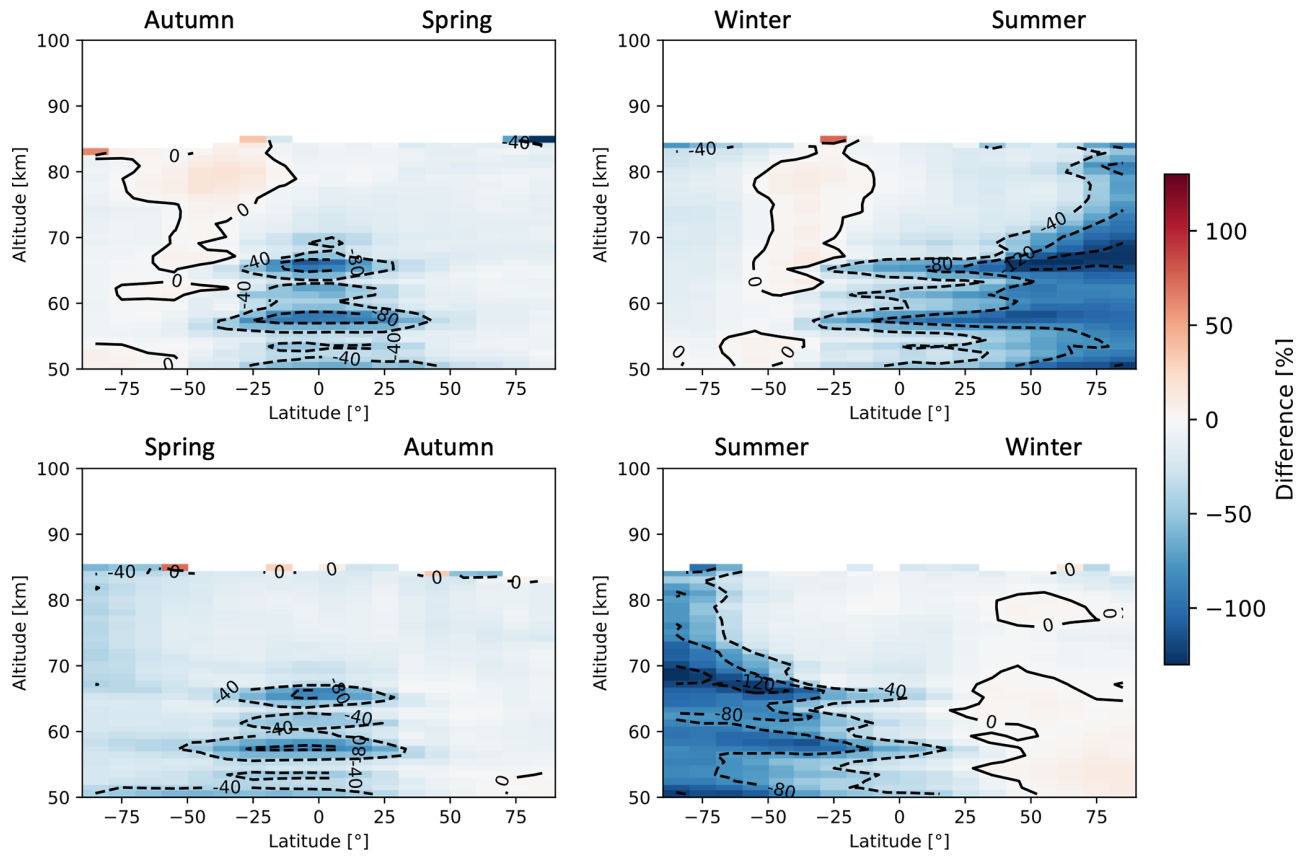

Figure A5. Seasonal zonal means of SMR-MLS relative differences averaged over the whole time between July 2004 and March 2019. The seasons are intended as the time between the solstice and the equinox. Note the different colour scale compared to the previous figures. 
Data availability. Odin/SMR v3.0 L2 data are publicly accessible at http://odin.rss.chalmers.se/level2 (last access: 8 September 2020; OdinSMR, 2020); MIPAS IMK/IAA L2 data (both NOM and MA/UA) can be downloaded upon registration at http://www.imk-asf.kit.edu/english/308.php (last access: 8 September 2020; KIT, 2020); ACE-FTS L2 data are available upon request at https://databace.scisat.ca/12signup.php (last access: 8 September 2020; ACE/SCISAT, 2020); MLS L2 data are available at https://doi.org/10.5067/Aura/MLS/DATA2005 (Schwartz et al., 2015).

Author contributions. FG developed the correction algorithm, processed the CO data, made most of the plots and wrote most of the text. KP, DM and PE initiated the project and supported FG throughout it. KP contributed to the writing of the text. PF performed the comparison study between SMR and the OSO radiometer and wrote the corresponding section. BR helped with the processing of the data. All co-authors contributed to the interpretation of the results and proofread the text.

Competing interests. The authors declare that they have no conflict of interest.

Special issue statement. This article is part of the special issue "New developments in atmospheric Limb measurements: Instruments, Methods and science applications (AMT/ACP inter-journal SI)". It is a result of the 10th international limb workshop, Greifswald, Germany, 4-7 June 2019.

Acknowledgements. The Chalmers team acknowledges support from the Swedish National Space Agency (grant no. Dnr 88/14 and 72/17). Odin is a Swedish-led satellite mission and is also part of the European Space Agency's (ESA) third-party mission programme. The reprocessing of the SMR data was supported by ESA (MesosphEO and Odin/SMR reprocessing projects). The authors would like to thank Julia Ringsby for her contribution to the correction algorithm. Bernd Funke acknowledges support by the Spanish MCINN (ESP2017-87143-R) and EC FEDER funds. The Atmospheric Chemistry Experiment is a Canadian-led mission mainly supported by the Canadian Space Agency. MLS research in Edinburgh was funded by NERC. The authors also thank the two anonymous reviewers for their helpful comments.

Financial support. This research has been supported by the Swedish National Space Agency (grant nos. Dnr 88/14 and Dnr 72/17) and the European Space Agency (Odin reprocessing, MesosphEO grant).

Review statement. This paper was edited by Helen Worden and reviewed by two anonymous referees.

\section{References}

ACE/SCISAT: ACE/SCISAT Database, Level 2 Data Access, available at: https://databace.scisat.ca/12signup.php, last access: 8 September 2020.

Allen, D. R., Stanford, J. L., López-Valverde, M. A., Nakamura, N., Lary, D. J., Douglass, A. R., Cerniglia, M. C., Remedios, J. J., and Taylor, F. W.: Observations of Middle Atmosphere CO from the UARS ISAMS during the Early Northern Winter 1991/92, J. Atmos. Sci., 56, 563-583, https://doi.org/10.1175/15200469(1999)056<0563:OOMACF>2.0.CO;2, 1999.

Baron, Ph., Ricaud, Ph., de la Noë, J., Eriksson, J. E. P., Merino, F., Ridal, M., and Murtagh, D. P.: Studies for the Odin submillimetre radiometer. II. Retrieval methodologys, Can. J. Phys., 80, 341-356, https://doi.org/10.1139/p01-150, 2002.

Barret, B., Ricaud, P., Santee, M. L., Attié, J.-L., Urban, J., Le Flochmoën, E., Berthet, G., Murtagh, D., Eriksson, P., Jones, A., de La Noë, J., Dupuy, E., Froidevaux, L., Livesey, N. J., Waters, J. W., and Filipiak, M. J.: Intercomparisons of trace gases profiles from the Odin/SMR and Aura/MLS limb sounders, J. Geophys. Res., 111, D21302, https://doi.org/10.1029/2006JD007305, 2006.

Bernath, P. F., McElroy, C. T., Abrams, M. C., Boone, C. D., Butler, M., Camy-Peyret, C., Carleer, M., Clerbaux, C., Coheur, P.-F., Colin, R., DeCola, P., DeMazière, M., Drummond, J. R., Dufour, D., Evans, W. F. J., Fast, H., Fussen, D., Gilbert, K., Jennings, D. E., Llewellyn, E. J., Lowe, R. P., Mahieu, E., McConnell, J. C., McHugh, M., McLeod, S. D., Michaud, R., Midwinter, C., Nassar, R., Nichitiu, F., Nowlan, C., Rinsland, C. P., Rochon, Y. J., Rowlands, N., Semeniuk, K., Simon, P., Skelton, R., Sloan, J. J., Soucy, M.-A., Strong, K., Tremblay, P., Turnbull, D., Walker, K. A., Walkty, I., Wardle, D. A., Wehrle, V., Zander, R., and Zou, J.: Atmospheric Chemistry Experiment (ACE): Mission overview, Geophys. Res. Lett., 32, L15S01, https://doi.org/10.1029/2005GL022386, 2005.

Boone, C. D., Nassar, R., Walker, K. A., Rochon, Y., McLeod, S. D., Rinsland, C. P., and Bernath, P. F.: Retrievals for the Atmospheric Chemistry Experiment Fourier-Transform Spectrometer, Appl. Optics., 44, 7218-7231, 2005.

Boone, C. D., Walker, K. A., and Bernath, P. F.: Version 3 Retrievals for the Atmospheric Chemistry Experiment Fourier Transform Spectrometer (ACE-FTS), The Atmospheric Chemistry Experiment ACE at 10: A Solar Occultation Anthology, pp. 103-127 A. Deepak Publishing, Hampton, Va., 2013.

Brasseur, G. P. and Solomon, S.: Aeronomy of the Middle Atmosphere, Springer, The Netherlands, 3rd edn., 2005.

Buehler, S. A., Mendrok, J., Eriksson, P., Perrin, A., Larsson, R., and Lemke, O.: ARTS, the Atmospheric Radiative Transfer Simulator - version 2.2, the planetary toolbox edition, Geosci. Model Dev., 11, 1537-1556, https://doi.org/10.5194/gmd-111537-2018, 2018.

Charlton, A. J. and Polvani, L. M.: A New Look at Stratospheric Sudden Warmings. Part I: Climatology and Modeling Benchmarks, J. Climate, 20, 449-469, https://doi.org/10.1175/JCLI3996.1, 2007.

Clancy, R. T., Muhleman, D. O., and Berge, G. L.: Microwave spectra of terrestrial mesospheric CO, J. Geophys. Res., 87, 5009, https://doi.org/10.1029/JC087iC07p05009, 1982.

Clerbaux, C., George, M., Turquety, S., Walker, K. A., Barret, B., Bernath, P., Boone, C., Borsdorff, T., Cammas, J. P., Catoire, V., 
Coffey, M., Coheur, P.-F., Deeter, M., De Mazière, M., Drummond, J., Duchatelet, P., Dupuy, E., de Zafra, R., Eddounia, F., Edwards, D. P., Emmons, L., Funke, B., Gille, J., Griffith, D. W. T., Hannigan, J., Hase, F., Höpfner, M., Jones, N., Kagawa, A., Kasai, Y., Kramer, I., Le Flochmoën, E., Livesey, N. J., López-Puertas, M., Luo, M., Mahieu, E., Murtagh, D., Nédélec, P., Pazmino, A., Pumphrey, H., Ricaud, P., Rinsland, C. P., Robert, C., Schneider, M., Senten, C., Stiller, G., Strandberg, A., Strong, K., Sussmann, R., Thouret, V., Urban, J., and Wiacek, A.: CO measurements from the ACE-FTS satellite instrument: data analysis and validation using ground-based, airborne and spaceborne observations, Atmos. Chem. Phys., 8, 2569-2594, https://doi.org/10.5194/acp-8-2569-2008, 2008.

Dee, D. P., Uppala, S. M., Simmons, A. J., Berrisford, P., Poli, P., Kobayashi, S., Andrae, U., Balmaseda, M. A., Balsamo, G., Bauer, P., Bechtold, P., Beljaars, A. C. M., van de Berg, L., Bidlot, J., Bormann, N., Delsol, C., Dragani, R., Fuentes, M., Geer, A. J., Haimberger, L., Healy, S. B., Hersbach, H., Hólm, E. V., Isaksen, L., Kållberg, P., Köhler, M., Matricardi, M., McNally, A. P., Monge-Sanz, B. M., Morcrette, J.-J., Park, B.-K., Peubey, C., de Rosnay, P., Tavolato, C., Thépaut, J.-N., and Vitart, F.: The ERA-Interim reanalysis: configuration and performance of the data assimilation system, Q. J. Roy. Meteorol. Soc., 137, 553597, https://doi.org/10.1002/qj.828, 2011.

de Zafra, R. L. and Muscari, G.: $\mathrm{CO}$ as an important high-altitude tracer of dynamics in the polar stratosphere and mesosphere, J. Geophys. Res., 109, D06105, https://doi.org/10.1029/2004JD005102, 2004.

Dupuy, É., Urban, J., Ricaud, P., Le Flochmoën, É., Lautié, N., Murtagh, D., De La Noë, J., El Amraoui, L., Eriksson, P., Forkman, P., Frisk, U., Jégou, F., Jiménez, C., and Olberg, M.: Stratomesospheric measurements of carbon monoxide with the Odin Sub-Millimetre Radiometer: Retrieval and first results, Geophys. Res. Lett., 31, L20101, https://doi.org/10.1029/2004GL020558, 2004.

Eriksson, P., Jiménez, C., and Buehlerb, S. A.: Qpack, a general tool for instrument simulation and retrieval work, J. Quant. Spectrosc. Ra., 91, 47-64, https://doi.org/10.1016/j.jqsrt.2004.05.050, 2005.

Eriksson, P., Ekström, M., Melsheimer, C., and Buehler, S.: Efficient forward modelling by matrix representation of sensor responses, Int. J. Remote Sens., 27, 1793-1808, https://doi.org/10.1080/01431160500447254, 2006.

Eriksson, P., Buehler, S. A., Davis, C. P., Emde, C., and Lemke, O.: ARTS, the atmospheric radiative transfer simulator, Version 2, J. Quant. Spectrosc. Ra., 112, 1551-1558, https://doi.org/10.1016/j.jqsrt.2011.03.001, 2011.

Errera, Q., Chabrillat, S., Christophe, Y., Debosscher, J., Hubert, D., Lahoz, W., Santee, M. L., Shiotani, M., Skachko, S., von Clarmann, T., and Walker, K.: Technical note: Reanalysis of Aura MLS chemical observations, Atmos. Chem. Phys., 19, 1364713679, https://doi.org/10.5194/acp-19-13647-2019, 2019.

Forkman, P., Christensen, O. M., Eriksson, P., Urban, J., and Funke, B.: Six years of mesospheric CO estimated from ground-based frequency-switched microwave radiometry at $57^{\circ} \mathrm{N}$ compared with satellite instruments, Atmos. Meas. Tech., 5, 2827-2841, https://doi.org/10.5194/amt-5-2827-2012, 2012.

Forkman, P., Christensen, O. M., Eriksson, P., Billade, B., Vassilev, V., and Shulga, V. M.: A compact receiver system for simultaneous measurements of mesospheric $\mathrm{CO}$ and $\mathrm{O} 3$, Geosci. Instrum.
Method. Data Syst., 5, 27-44, https://doi.org/10.5194/gi-5-272016, 2016.

Frisk, U., Hagström, M., Ala-Laurinaho, J., et al.: The Odin satellite I. Radiometer design and test, A\&A, 402, L27-L34, https://doi.org/10.1051/0004-6361:20030335, 2003.

Froidevaux, L., Livesey, N. J., Read, W. G., Jiang, Y. B., Jimenez, C., Filipiak, M. J., Schwartz, M. J., Santee, M. L., Pumphrey, H. C., Jiang, J. H., Wu, D. L., Manney, G. L., Drouin, B. J., Waters, J. W., Fetzer, E. J., Bernath, P. F., Boone, C. D., Walker, K. A., Jucks, K. W., Toon, G. C., Margitan, J. J., Sen, B., Webster, C. R., Christensen, L. E., Elkins, J. W., Atlas, E., Lueb, R. A., and Hendershot, R.: Early validation analyses of atmospheric profiles from EOS MLS on the aura Satellite, IEEE Trans. Geosci. Rem. Sens., 44, 1106-1121, https://doi.org/10.1109/TGRS.2006.864366, 2006.

Funke, B., López-Puertas, M., Bermejo-Pantaleón, D., von Clarmann, T., Stiller, G. P., Höpfner, M., Grabowski, U., and Kaufmann, M.: Analysis of nonlocal thermodynamic equilibrium $\mathrm{CO} 4.7 \mu \mathrm{m}$ fundamental, isotopic, and hot band emissions measured by the Michelson Interferometer for Passive Atmospheric Sounding on Envisat, J. Geophys. Res., 112, D11305, https://doi.org/10.1029/2006JD007933, 2007.

Funke, B., López-Puertas, M., García-Comas, M., Stiller, G. P., von Clarmann, T., Höpfner, M., Glatthor, N., Grabowski, U., Kellmann, S., and Linden, A.: Carbon monoxide distributions from the upper troposphere to the mesosphere inferred from $4.7 \mu \mathrm{m}$ non-local thermal equilibrium emissions measured by MIPAS on Envisat, Atmos. Chem. Phys., 9, 2387-2411, https://doi.org/10.5194/acp-9-2387-2009, 2009.

Garcia, R. R., López-Puertas, M., Funke, B., Marsh, D. R., Kinnison, D. E., Smith, A. K., and González-Galindo, F.: On the distribution of $\mathrm{CO}_{2}$ and $\mathrm{CO}$ in the mesosphere and lower thermosphere, J. Geophys. Res.-Atmos., 119, 5700-5718, https://doi.org/10.1002/2013JD021208, 2014.

Garcia, R. R., López-Puertas, M., Funke, B., Kinnison, D. E., Marsh, D. R., and Qian, L.: On the secular trend of $\mathrm{CO}_{\mathrm{x}}$ and $\mathrm{CO}_{2}$ in the lower thermosphere, J. Geophys. Res. Atmos., 121, 3634-3644, https://doi.org/10.1002/2015JD024553, 2016.

Hamilton, K.: MIDDLE ATMOSPHERE|Semiannual Oscillation, Encyclopedia of Atmospheric Sciences, 2nd edn., Academic Press, 26-29, https://doi.org/10.1016/B978-0-12-3822253.00233-4, 2015.

Karlsson, B., Gumbel, J., Stegman, J., Lautier, N., Murtagh, D., and Odin, Team: Studies of Noctilucent Clouds by the Odin Satellite, in: Proceedings of the 35th COSPAR Scientific Assembly, 35, 1921, 2004.

Kiefer, M. and Lossow, S.: MIPAS-IMK/IAA L2 Data ReadMe, FMI-TN-MesosphEO-WP4-003, Version 1.0, 2017.

KIT: Available Data, Karlsruhe Institute of Technology, available at: http://www.imk-asf.kit.edu/english/308.php, last access: 8 September 2020.

Lee, J. N., Wu, D. L., Manney, G. L., Schwartz, M. J., Lambert, A., Livesey, N. J., Minschwaner, K. R., Pumphrey, H. C., and Read, W. G.: Aura Microwave Limb Sounder observations of the polar middle atmosphere: Dynamics and transport of $\mathrm{CO}$ and $\mathrm{H}_{2} \mathrm{O}$, J. Geophys. Res., 116, D05110, https://doi.org/10.1029/2010JD014608, 2011. 
Lee, J. N., Wu, D. L., Ruzmaikin, A., and Fontenla, J.: Solar cycle variations in mesospheric carbon monoxide, J. Atmos. SolarTerrest. Phys., 170, 21-34, 2018.

Livesey, N. J., Read, W. G., Wagner, P. A., Froidevaux, L., Lambert, A., Manney, G. L., Millán Valle, L. F., Pumphrey, H. C., Santee, M. L., Schwartz, M. J., Wang, S., Fuller, R. A., Jarnot, R. F., Knosp, B. W., Martinez, E., and Lay, R. R.: Earth Observing System (EOS) Aura Microwave Limb Sounder (MLS) Version 4.2x Level 2 data quality and description document, Tech. Rep. D-33509 Rev. D, JPL, 2018.

Manney, G. L., Harwood, R. S., MacKenzie, I. A., Minschwaner, K., Allen, D. R., Santee, M. L., Walker, K. A., Hegglin, M. I., Lambert, A., Pumphrey, H. C., Bernath, P. F., Boone, C. D., Schwartz, M. J., Livesey, N. J., Daffer, W. H., and Fuller, R. A.: Satellite observations and modeling of transport in the upper troposphere through the lower mesosphere during the 2006 major stratospheric sudden warming, Atmos. Chem. Phys., 9, 47754795, https://doi.org/10.5194/acp-9-4775-2009, 2009.

Minschwaner, K., Manney, G. L., Livesey, N. J., Pumphrey, H. C., Pickett, H. M., Froidevaux, L., Lambert, A., Schwartz, M. J., Bernath, P. F., Walker, K. A., and Boone, C. D.: The photochemistry of carbon monoxide in the stratosphere and mesosphere evaluated from observations by the MicrowaveLimb Sounder on the Aura satellite, J. Geophys. Res.,115, D13303, https://doi.org/10.1029/2009JD012654, 2010.

OdinSMR: Level2 data dashboard, available at: http://odin.rss. chalmers.se/level2, last access: 8 September 2020.

Oelhaf, H.: MIPAS Mission Plan, Issue 4, Version 3, ESA Technical Note ENVI-SPPA-EOPG-TN-07-0073, 2008.

Orsolini, Y. J., Limpasuvan, V., Pérot, K., Espy, P., Hibbins, R., Lossow, S., Raaholt Larsson, K., and Murtagh, D.: Modelling the descent of nitric oxide during the elevated stratopause event of January 2013, J. Atmos. Solar-Terrest. Phys., 155, 50-61, https://doi.org/10.1016/j.jastp.2017.01.006, 2017.

Pérot, K., Urban, J., and Murtagh, D. P.: Unusually strong nitric oxide descent in the Arctic middle atmosphere in early 2013 as observed by Odin/SMR, Atmos. Chem. Phys., 14, 8009-8015, https://doi.org/10.5194/acp-14-8009-2014, 2014.

Picone, J. M., Hedin, A. E., Drob, D. P., and Aikin, A. C.: NRLMSISE-00 empirical model of the atmosphere: Statistical comparisons and scientific issues, J. Geophys. Res., 107, 1468, https://doi.org/10.1029/2002JA009430, 2002.

Pumphrey, H. C., Filipiak, M. J., Livesey, N. J., Schwartz, M. J., Boone, C., Walker, K. A., Bernath, P., Ricaud, P., Barret, B., Clerbaux, C., Jarnot, R. F., Manney, G. L., and Waters, J. W.: Validation of middle-atmosphere carbon monoxide retrievals from the Microwave Limb Sounder on Aura, J. Geophys. Res., 112, D24S38, https://doi.org/10.1029/2007JD008723, 2007.

Randall, C. E., Rusch, D. W., Bevilacqua, R. M., Hoppel, K. W., Lumpe, J. D., Shettle, E., Thompson, E., Deaver, L., Zawodny, J., Kyrö, E., Johnson, B., Kelder, H., Dorokhov, V. M., KönigLanglo, G., and Gil, M.: Validation of POAM III ozone: comparison with ozonesonde and satellite data, J. Geophys. Res., 108, 4367, https://doi.org/10.1029/2002JD002944, 2003.

Rodgers, C. D.: Inverse methods for atmospheric sounding: Theory and practise, World Scientific Publishing, 1st edn., 2000.
Rothman, L. S., Gordon, I. E., Babikov, Y., Barbe, A., Chris Benner, D., Bernath, P. F., Birk, M., Bizzocchi, L., Boudon, V., Brown, L. R., Campargue, A., Chance, K., Cohen, E. A., Coudert, L. H., Devi, V. M., Drouin, B. J., Fayt, A., Flaud, J.-M., Gamache, R. R., Harrison, J. J., Hartmann, J.-M., Hill, C., Hodges, J. T., Jacquemart, D., Jolly, A., Lamouroux, J., Le Roy, R. J., Li, G., Long, D. A., Lyulin, O. M., Mackie, C. J., Massie, S. T., Mikhailenko, S., Müller, H. S. P., Naumenko, O. V., Nikitin, A. V., Orphal, J., Perevalov, V., Perrin, A., Polovtseva, E. R., Richard, C., Smith, M. A. H., Starikova, E., Sung, K., Tashkun, S., Tennyson, J., Toon, G. C., Tyuterev, Vl. G., and Wagner, G.: The HITRAN2012 molecular spectroscopic database, J. Quant. Spectrosc. Ra., 130, 4-50, https://doi.org/10.1016/j.jqsrt.2013.07.002, 2013.

Rydberg, B., Eriksson, P., Kiviranta, J., Ringsby, J., Skyman, A., and Murtagh, D.: Odin/SMR Algorithm Theoretical Basis Document: Level 1 Processing, Technical Report, Chalmers University of Technology, Department of Space, Earth and Environment, available at: http://odin.rss.chalmers.se/\#documents (last access: 8 September 2020), 2017.

Schoeberl, M. R., Douglass, A. R., Hilsenrath, E., Bhartia, P. K., Beer, R., Waters, J. W., Gunson, M. R., Froidevaux, L., Gille, J. C., Barnett, J. J., Levelt, P. F., and DeCola, P.: Overview of the EOS Aura Mission, IEEE Trans. Geosci. Remote Sensing, 44, 1066-1074, https://doi.org/10.1109/TGRS.2005.861950, 2006.

Schwartz, M., Pumphrey, H., Livesey, N., and Read, W.: MLS/Aura Level 2 Carbon Monoxide (CO) Mixing Ratio V004, Greenbelt, MD, USA, Goddard Earth Sciences Data and Information Services Center (GES DISC), https://doi.org/10.5067/Aura/MLS/DATA2005, 2015.

Sheese, P. E., Boone, C. D., and Walker, K. A.: Detecting physically unrealistic outliers in ACE-FTS atmospheric measurements, Atmos. Meas. Tech., 8, 741-750, https://doi.org/10.5194/amt-8741-2015, 2015.

Sheese, P. E., Walker, K. A., Boone, C. D., Bernath, P. F., Froidevaux, L., Funke, B., Raspollini, P., and von Clarmann, T.: ACE-FTS ozone, water vapour, nitrous oxide, nitric acid, and carbon monoxide profile intercomparisons with MIPAS and MLS, J. Quant. Spectrosc. Ra., 186, 63-80, https://doi.org/10.1016/j.jqsrt.2016.06.026, 2016.

Solomon, S., Garcia, R. R., Olivero, J. J., Bevilacqua, R. M., Schwartz, P. R., Clancy, R. T., and Muhleman, D. O.: Photochemistry and Transport of Carbon Monoxide in the Middle Atmosphere, J. Atmos. Sci., 42, 10721083, 1985.

Vignon, E. and Mitchell, D. M.: The stratopause evolution during different types of sudden stratospheric warming event, Clim. Dynam., 44, 3323, https://doi.org/10.1007/s00382-014-2292-4, 2015.

Waters, J. W., Froidevaux, L., Jarnot, R. F., Read, W. G., Pickett, H. M., Harwood, R. S., Cofield, R. E., Filipiak, M. J., Flower, D. A., Livesey, N. J., Manney, G. L., Pumphrey, H. C., Santee, M. L., Siegel, P. H., and Wu, D. L.: An Overview of the EOS MLS Experiment, version 2.0, JPL D-15745, ATBD-MLS-01, 2004.

Zander, R., Leclercq, H., and Kaplan, L. D.: Concentration of carbon monoxide in the upper stratosphere, Geophys. Res. Lett., 8, 365-368, https://doi.org/10.1029/GL008i004p00365, 1981. 